\title{
Microtubule Assembly and Turnover in Growing Axons
}

\author{
Yan Li and Mark M. Black \\ Department of Anatomy and Cell Biology, Temple University School of Medicine, Philadelphia, Pennsylvania 19140
}

We have shown previously that axonal microtubules (MTs) are composite, consisting of two distinct domains that differ in their content of tyrosinated $\alpha$-tubulin (tyr-tub). One domain is poor in tyr-tub and is situated at the minus end of the MT. The other domain is rich in tyr-tub and extends from the plus end of the tyr-tub-poor domain to the end of the MT. We have proposed that the spatial variation in the relative content of tyr-tub along individual MTs reflects corresponding variations in their dynamic properties. The present experiments have tested this hypothesis directly by microinjecting biotin-labeled tubulin (Bttub) into cultured sympathetic neurons and then quantifying the appearance of Bt-tub in the tyr-tub-rich and tyr-tub-poor polymer of the axon. Bt-tub appeared in axonal MTs with a half-life $\left(t_{1 / 2}\right)$ of $\sim 2.2 \mathrm{hr}$. This time course reflected an average of two distinct components corresponding to the tyr-tub-rich and tyrtub-poor polymer that had apparent $t_{1 / 2}$ values of $\sim 1.3$ and 3.3 $\mathrm{hr}$, respectively. In individual MTs, Bt-tub first appeared in the tyr-tub-rich domain and then only later appeared in the tyr-tubpoor domain. Also, the appearance of Bt-tub in the tyr-tub-rich polymer typically began precisely at its origin from the tyr-tubpoor domain, indicating that the tyr-tub-poor polymer is assembly-competent and nucleates the assembly of tyr-tubrich polymer locally within the axon. The stability properties of axonal MTs are discussed in terms of organizing MT assembly locally in the axon and generating long MTs for growing long axons.

Key words: cultured sympathetic neurons; microtubules; microtubule turnover; axon growth; microinjection; biotin-tubulin
Individual microtubules (MTs) of the axon are composite, consisting of two distinct domains that differ in their content of post-translationally modified tubulin subunits. This was revealed first by staining for tyrosinated $\alpha$-tubulin (tyr-tub) (Baas and Black, 1990; Brown et al., 1993). Individual MTs consisted of two domains that differed dramatically in their staining for tyr-tub. One domain stained poorly for tyr-tub, whereas the other domain stained strongly, and the transition between these domains was relatively abrupt. These two domains also differ dramatically, by $\sim 35$-fold, in their sensitivity to nocodazole, a potent MTdepolymerizing drug (Baas et al., 1991).

In many cell types, the relative content of tyr-tub in MTs varies inversely with polymer age (Bré et al., 1987; Gundersen et al., 1987; Kreis, 1987; Schulze et al., 1987; Sherwin et al., 1987; Webster et al., 1987; Wehland and Weber, 1987; Sherwin and Gull, 1989). As a result, recently assembled MTs contain greater relative amounts of tyr-tub than do older, more long-lived MTs. Similarly, in some cell types MT sensitivity to depolymerizing drugs also correlates with metabolic stability, and MTs that turn over rapidly depolymerize faster than MTs that turn over slowly (Cassimeris et al., 1986; Kreis, 1987; Wadsworth and McGrail, 1990; Prescott et al., 1992). If these considerations apply to axonal MTs, then the tyr-tub-poor domains of these MTs are more long-lived than their tyr-tub-rich domains. On this basis, we have suggested that the tyr-tub-rich domains assemble locally within the axon by elongation from the tyr-tub-poor domains. Implicit in

Received Aug. 9, 1995; revised Oct. 16, 1995; accepted Oct. 18, 1995.

This work was supported by NIH Grant NS17681 to M.M.B. We thank Dr. Chloe Bulinski, Columbia University School of Medicine, for providing antibody against tyrosinated $\alpha$-tubulin.

Correspondence should be addressed to Dr. Mark M. Black, Department of Anatomy and Cell Biology, Temple University School of Medicine, 3400 N. Broad Street, Philadelphia, PA 19140.

Copyright (C) 1996 Society for Neuroscience $0270-6474 / 96 / 160531-14 \$ 05.00 / 0$ this perspective is that the tyr-tub-poor domains are relatively long-lived structures for nucleating MT assembly within the axon.

This picture of axonal MTs comes from the assumption that spatial variations in the relative tyr-tub content and drug sensitivity along individual MTs reflect corresponding variations in dynamic properties. In the present studies, we have evaluated directly the stability properties of axonal MTs by microinjecting biotin-labeled tubulin (Bt-tub) into cultured neurons and then quantifying the time course by which Bt-tub appeared in the tyr-tub-rich and tyr-tub-poor polymer of the axon. The results show that the tyr-tub-poor polymer is more long-lived than the tyr-tub-rich polymer, by a factor of two- to threefold, and also that the tyr-tub-poor polymer is assembly-competent and responsible for nucleating the assembly of tyr-tub-rich polymer locally in the axon. In addition, the turnover behavior of axonal MTs, average half-life $\left(t_{1 / 2}\right)$ of $\sim 130 \mathrm{~min}$, is very different from that reported for fibroblasts and epithelial cells $\left[t_{1 / 2}\right.$ of seconds to minutes (Salmon et al., 1984; Cassimeris et al., 1986, 1988; Geuens et al., 1989; Pepperkok et al., 1990; Sheldon and Wadsworth, 1993)]. The specialized stability properties of axonal MTs are discussed in terms of generating long MTs for growing long axons.

\section{MATERIALS AND METHODS}

Materials. Culture media were ubtained from Gibco (Grand Island, NY). Supplements for culture media were obtained from either Gibco or Sigma (St. Louis, MO), except for nerve growth factor, which was purified from mouse salivary glands according to Mobley et al. (1976). Other reagents were obtained from Sigma unless indicated otherwise.

Cell culture. Rat sympathetic neurons were grown on glass coverslips coated with polylysine and laminin (Collaborative Biomedical Products, Bedford, MÄ) as described previously (Brown et al., 1992). Cells were cultured in L-15 growth medium as described by Mains and Patterson (1973), except that methocel was not used and $1 \%$ fetal calf serum was used in place of adult rat serum. This medium maintains $\mathrm{pH} 7.3$ in air.

Microinjection of $B t-t u b$. Tubulin was purified from calf brain as described by Mitchison and Kirschner (1984) and then biotinylated by using biotin- $N$-hydroxysuccinimide ester (Molecular Probes, Eugene, OR) fol- 
lowing the protocol of Hyman et al. (1991). After the final assembly step the Bt-tub-containing MTs were depolymerized in injection buffer (50 $\mathrm{mm}$ potassium glutamate, $0.5 \mathrm{~mm}$ glutamic acid, $0.5 \mathrm{~mm} . \mathrm{MgCl}_{2}: \mathrm{pH} 6.5$ ), clarificd by centrifugation, and then stored in aliquots ranging in concentration from 19 to $32 \mathrm{mg} / \mathrm{ml}$ [protein was determined by the BCA assay (Pierce Chemical, Rockford, IL) using bovine serum albumin as a standard]. For storage, the Bt-tub was frozen in liquid $\mathrm{N}_{2}$ and then stored at $-80^{\circ} \mathrm{C}$. Immediately before use, the tubulin was thawed rapidly, diluted to the desired concentration with injection buffer $(4.4 \mathrm{mg} / \mathrm{ml}$ unless indicated otherwise), and then clarified by centrifugation at $200,000 \times g$ for $10 \mathrm{~min}$ in a Beckman TL-100 ultracentrifuge (Beckman Instruments, Palo Alto, CA) to remove protein aggregates. The clarified Bt-tub then was pressure-injected into cultured neurons using an Eppendorf injector (Hamburg, Germany) and micropipettes with tip diameter $\leq 0.5 \mu \mathrm{m}$ [pipettes were prepared immediately before use with a Sutter Instruments P-97 pipette puller (Leveroni Court, Novato, CA)].

In all of the studies presented here, neurons were microinjected between 18 and 22 hr after plating. Only neurons with well developed axons (length ranging from 200 to $500 \mu \mathrm{m}$ ) and well spread growth cones were selected for microinjection. Typically, $50-80 \%$ of the neurons survived microinjection, and these neurons continued growing at normal rates for at least the next $8 \mathrm{hr}$. This was determined by imaging the neurons immediately after injection and then at intervals of up to $8 \mathrm{hr}$ (see below for details of imaging and analysis methods). Noninjected cells in the same dish were monitored similarly. The noninjected cells grew at an average rate of $18 \mu \mathrm{m} / \mathrm{hr}$ (range $13-25 \mu \mathrm{m} / \mathrm{hr} ; n=4$ ). The injected sells grew at an average rate of $18 \mu \mathrm{m} / \mathrm{hr}$ (range $12-23 \mu \mathrm{m} / \mathrm{hr} ; n=10$ ). Clearly, the injection procedure did not impair axon growth.

Cell extraction and fixation. To examine the movement of the injected tubulin from the injection site in the cell body into the axon, neurons were microinjected with Bt-tub ( $4.4 \mathrm{mg} / \mathrm{ml}$ final concentration), and then at times ranging from $\sim 3$ to 120 min thereafter, the neurons were rinsed once with phosphate-buffered saline (PBS) and once with PHEM $(60 \mathrm{mM}$ 1,4-piperazinediethanesulfonic acid, $25 \mathrm{mM} \mathrm{4-(2-}$ hydroxyethyl)-1-piperazine-ethanesulfonic acid, $10 \mathrm{~mm}$ ethylene glycol bis ( $\beta$-aminoethyl)ether $N, N, N^{\prime}, N^{\prime}$-tetra-acetic acid, and $2 \mathrm{mM} \mathrm{MgCl}_{2}, \mathrm{pH}$ 6.9) (Schliwa and van Blerkom, 1981), and then fixed without extraction with PHEM containing $2 \% p$-formaldehyde $+0.05 \%$ glutaraldehyde at room temperature for 10 min. Fixed cells were rinsed with PBS and then permeabilized by incubation with $1 \%$ Triton $X-100$ in PBS for $15 \mathrm{~min}$. Subsequently, the dishes were rinsed with PBS, treated with three $5 \mathrm{~min}$ changes of sodium borohydride (Sigma; $10 \mathrm{mg} / \mathrm{ml}$ in a 1:1 mixture of PBS and methanol), rinsed with PBS again, and then double-stained for $\beta$-tubulin and Bt-tub as described below. The distribution of total Bt-tub in the axons of injected neurons then was quantified as described below.

To examine the incorporation of Bt-tub into axonal MTs, cells microinjected with Bt-tub were processed at times ranging from 2 to $20 \mathrm{hr}$ after injection. Cells were extracted under conditions that remove unassembled tubulin, stabilize existing MTs, and cause the axonal MT array to fray apart so that individual MTs can be visualized readily using immunofluorescence procedures (Brown et al, 1993). Specifically, neurons were rinsed once with PBS and once with PHEM and then extracted for 5 min with PHEM containing $10 \mu \mathrm{M}$ taxol (a gift from Ms. Nancita Lomax, National Cancer Institute), protease inhibitors ( $0.2 \mathrm{U}$ of trypsin inhibitory $/ \mathrm{ml}$ aprotinin, and $10 \mu \mathrm{g} / \mathrm{ml}$ each leupeptin, chymostatin and antipain), and $1 \%$ Triton X-100 $+0.4 \mathrm{M} \mathrm{NaCl}$ or $\mathrm{KCl}$. The inclusion of $\mathrm{NaCl}$ or $\mathrm{KCl}$ in the extraction buffer causes a loosening of the axonal MT array so that individual MTs separate from each other for variable distances along their length. We call this phenomenon fraying. Individual MTs often can be traced for several tens of microns along their length and, in many cases, one end of this polymer, usually the plus end, can be identified unambiguously.

After extraction, the cells were fixed with PHEM containing $2 \%$ $p$-formaldehyde $+0.3 \%$ glutaraldehyde at room temperature for $10 \mathrm{~min}$, rinsed with PBS, treated with three 5 min changes of sodium borohydride $(10 \mathrm{mg} / \mathrm{ml}$ in a 1:1 mixture of PBS and methanol), rinsed with PBS again, and then double-stained for tubulin and Bt-tub as described below. The stained cells were analyzed to determine the proportion of polymer with or without Bt-tub (see below).

Immunofluorescence procedures. Cells were incubated with blocking solution [PBS containing $0.3 \mathrm{M} \mathrm{NaCl}, 0.1 \%$ Triton $\mathrm{X}-100,1 \%(\mathrm{v} / \mathrm{v})$ normal donkey serum, and $4 \%(\mathrm{w} / \mathrm{v})$ bovine serum albumin] for $15 \mathrm{~min}$ just before incubation with primary antibodies (Abs) and again before incubation with secondary Abs. In addition, all Abs were diluted in blocking solution and then clarified before use by centrifugation at $200,000 \times g$ for
10 min in a Beckman TL-100 ultracentrifuge. All secondary Abs (AffniPure grade, preadsorbed for minimum cross-reactivity) were purchased from Jackson Immunoresearch (West Grove, PA). Incubations with primary Abs were conducted for $45 \mathrm{~min}$ at $37^{\circ} \mathrm{C}$, and incubations with secondary $\mathrm{Abs}$ were conducted for $30 \mathrm{~min}$ at $37^{\circ} \mathrm{C}$; after incubation with secondary Abs, cells were rinsed with PBS and then mounted in 50\% (w/v) glycerol containing $10 \mathrm{mg} / \mathrm{m} / \mathrm{n}$-propyl gallate.

Neurons extracted to produce fraying of the MT array of the axon were double-stained to reveal Bt-tub and either $\beta$-tubulin or tyr-tub according to one of the following protocols. To double-stain for $\beta$-tubulin and $\mathrm{Bt}$-tub, cells were incubated simultaneously with a mouse monoclonal $\mathrm{Ab}$ against $\beta$-tubulin (Amersham, Arlington Heights, II) (Blose et al., 1984), which was diluted 1:100, and a rabbit polyclonal Ab against biotin (Enzo Biochemicals, New York, NY), which was diluted 1:100. After extensive rinsing with PBS and then reblocking, the cells were incubated with rhodamine $(\mathrm{Rh})$-labeled goat anti-rabbit $\mathrm{Ab}$, diluted 1:200, rinsed extensively with PBS, reblocked, and then incubated with a mixture of $\mathrm{Rh}$-labeled rabbit anti-goat $\mathrm{Ab}$ and fluorescein (FI)-labeled donkey anti. mouse $\mathrm{Ab}$, which were diluted 1:200 and 1:50, respectively. To doublestain for tyr-tub and Bt-tub. cells were incubated simultaneously with a rabbit polyclonal $\mathrm{Ab}$ against tyr-tub [diluted 1:400-1:3200; generously provided by Dr. Chlce Bulinski. Columbia University School of Medicine (Gundersen et al., 1987)] and a Cy3-labeled mouse monoclonal Ab against Bt-tub (diluted 1:100, Jackson. Immunoresearch). After rinsing with PBS and then reblocking, the cells were incubated with a mixture of Cy3-labeled donkey anti-mouse $\mathrm{Ab}$ and Fl-labeled donkey anti-rabbit $\mathrm{Ab}$, which were diluted 1:100 and 1:50, respectively. These latter staining conditions permit visualization of the tyr-tub-rich and -poor polymer of the axon (Brown et al., 1993) as well as the MT polymer with Bt-tub. Thus, we used these preparations to evaluate the time course by which Bt-tub appeared in these types of polymer.

Some experiments used the Ab-blocking staining procedure described by Schulze and Kirschner (1987). For these analyses, cells were injected with Bt-tub $2 t$ a concentration of $32 \mathrm{mg} / \mathrm{ml}$. After extraction and fixation, as described above, the cells were incubated with the rabbit polyclonal $\mathrm{Ab}$ against biotin (diluted 1:100), rinsed well with PBS, and then incubated sequentially with four secondary Ahs: first with $\mathrm{Rh}$-goat anti-rahbit $\mathrm{Ah}$, diluted 1:200; second with Rh-rabbit anti-goat $\mathrm{Ab}$, diluted 1:200; third with unlabeled goat anti-rabbit $\mathrm{Ab}$, diluted 1:100; and, finally, with unlabeled rabbit anti-goat $\Lambda \mathrm{b}$, diinted 1:100. The cells were rinsed extensively and reblocked after each secondary $\mathrm{Ab}$ incubation. Then the cells were incubated with a mouse monoclonal $\mathrm{Ab}$ against $\beta$-tubulin, diluted 1:100, rinsed extensively with PBS, and then incubated with an Fl-donkey anti-mouse $\mathrm{Ab}$, which was diluted 1:50.

Image acquisition and analysis. For experiments examining the effects of microiniection on axon growth, cells were observed by phase contrast microscopy using a Zeiss Axiovert 35 inverted microscope (Zeiss, Thornwood, NY). Images of cells were captured with a Newvicon camera (Hamamatsu Photonic systems, Bridgewater, NJ) interfaced to an Apple Quadra 950 computer using a Pixelpipeline framegrabber board (Perceptics, Knoxville, TN) and the Oncor Imaging processing and analysis software package (Rockville, MD). Axon lengths were determined on the basis of a one-pixel-wide line drawn down the center of the axon using programs written in our laboratory using the Oncor Imaging programming language.

For analyses of the movement of Bt-tub in axons and the incorporation of Bt-tub into axonal MTs, cells were observed by epifluorescence microscopy using a Zeiss Axiovert 135 inverted microscope. The cells were illuminated with a $100 \mathrm{~W}$ mercury arc lamp and observed using Fl (Zeiss filter set 10) and Rh (Zeiss filter set 14) filter sets. A heat-absorbing colored glass filter (BG40) was inserted into the light path between the light source and the filter block. Images were obtained with a CH250cooled charge-coupled device (CCD) camera (Photometrics, Tucson, AZ) equipped with a Thompson 7883 CCD chip. The array size of the CCD chip was $384 \times 576$, and the readout rate was $500 \mathrm{kHz}$. The temperature of the chip was maintained at approximately $-42^{\circ} \mathrm{C}$. Image acquisition was performed on an Apple Macintosh Quadra 950 computer using 3 II N:200 cumera controller board and the Oncor Imaging processing and analysis software package. Illumination of the sample was controlled using a Uniblitz electronic shutter (Vincent, Rochester, NY), which was operated automatically from the Oncor Imaging software using a MAC 2000 Communications Interface Module (Ludl Electronics, Hawthorne, NY)

Images were acquired using the full usable area of the CCD chip, which measured $382 \times 576$ pixels, and were stored in full 12-bit format on 
magneto-optical disks using Pinnacle optical disk drives (Pinnacle Micro, Irvine, CA). Before capturing a series of images, an iristantaneous readout of the bias voltage offset on the chip was saved and subsequentily subiracted from each exposed image. Dark current [0.133 analog-todigital units (ADU)/sec] was not significant for the exposure times used in these studies. The magnification of the CCD images was calibrated using a stage micrometer. For maximum precision, all measurements of fluorescence intensity (sec below) were performed on the 12-bit images. For presentation, images were scaled to 8 bits.

To evaluate the time course by which Bt-tub moved from the injection site in the cell body toward the axon tip, cells fixed without extracticn and then double-stained for $\beta$-tubulin and Bt-tub were imaged using a $25 \times i$ 0.8 N.A. Plan neofluar oil-immersion objective to capture the entrire length of the axons in single images. The distributions of total tubulin and Bt-tub in these axons then were quantified using the segmented mask procedure (Brown et aí., 1992, 1993; Biack et al., 1994). Briefly, the $\beta$-tubulin image was used to generate a mask of the axon. The mask was

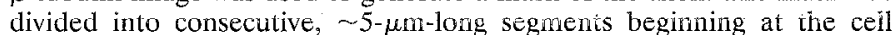
body and continuing to the axon tip. The segmented mask was then overlaid on the original $\mathrm{Rh}$ and $\mathrm{Fl}$ images depicting the distribution of Bt-tub and total $\beta$-iubulin, respectively. This allowed us to define segments in the fluorescent images that corresponded to the segments in the mask. To correct for background fluorescence in cach image, an arerage background pixel intensity was calculated for each segment and then subtracted from each pixel within that segment. Then the total fiuorescence intensity for the segments in each image was calculated by summing the corrected intensities of the pixels comprising each segment. These procedures have been incorporated into a single interactive application program written in the Oncor Imaging programming language. A synopsis of these procedures is presented in Brown et al. (1992), and a more detailed description wili be provided on request.

On the basis of analyses of noninjected cells that were stained and imaged identically to the injected cells in the same cultures, we determined that the nonspecific $\mathrm{R} h$ glow in the axon was a constant percentage of the Fl glow caused by $\beta$-tubulin staining ( $5 \%$ for the exposure times used). Thus, for each injected cell we corrected the $\mathrm{Rh}$ staining atcributable to Bt-tub for this nonspecific component. Then the fiuorescence intensity of each segment, measured as arbitrary ADU, was piotted against distance along the axon (sce Fig. 1), and the front of Bt-tub was identified as the position along the axon at which the intensity of Bt-tub staining dropped to zero (see Fig. 1).

To measure the time course of appearance of Bt-tub in axonal MTs, we calculated the proportion of polymer within the axon that contained Bt-tub at various times after injection. These data cams from ceils extracted for fraying, as described above, and then doubie-stained to reveal $\mathrm{Bt}-\mathrm{tub}$ and either $\beta$-tubulin or tyr-tub. The procedures for fraying the axonal MT array produce variable degrees of fraying (Brown er al., 1993). Thus, to maximize the extent to which our turnover measurements reflect the behavior of the entire axonal MT array, we restricted these analyses to cells that exhibited extensive fraying (see Fig. 3). Frayed ceils were imaged with a $100 \times / 1.3$ Plan neofluar oil-immersion objective, and a sufficient number of images was obtained to inciude most or all of each axon from its origin at the cell body to the axon tip. We rneasured ine length of all profiles of individual Mrs discernible in each image and inen determined the lengths of these profiles that also stainea for Bt-tub. From these two values, we calculated the proporrion of MT polymer that contained Bt-tub (see Figs. 5, 7). MT lengths were measured using the Oncor Imaging software and application programs written in inis laboratory using the Oncor Imaging programming language.

\section{RESULTS}

Our goal in the present experiments was to quantify the turnover behavior of MTs in actively growing axons and thereby test the hypothesis that individual MTs in growing axons consist of distinct domains that differ in their dynamic behavior. Toward this end, we used cultures of rat sympathetic neurons as a model system because these neurons adapt casily to the culture environment and, within a few hours after plating, begin extending axons that elongate steadily for many days. Neurons were injected with Bt-tub at 18-22 hr after plating, when they already had relatively long $(200-500 \mu \mathrm{m})$ branched axons, and the axons of injected cells continued growing at an average rate of $\sim 20 \mu \mathrm{m} / \mathrm{hr}$ (see Materials and Methods). At varying times after injection, the neurons were processed to reveal the MT polymer with Bt-tub and the MT polymer without Bt-tub. Because the neurons had relatively long axons at the time of injection, the time course by which $\mathrm{B}$-tub appeared in axonal MTs reflects a combination of the time required for the injected tubulin to move (by diffusion and by active transport) from the site of injection in the cell body into the axon and for the assembly of Bt-tub into MTs within the axon. The nexi section evaluates the time course of tubulin movement from the cell body into the axon. Then we present our results on the appearance of Bt-tub in axonal MTs.

\section{Movement of microinjected tubulin along the axon}

For these analyses neurons were microinjected with Bt-tub, and then at times ranging from $\sim 3$ to 120 min thereafter they were fixed (without extraction) and stained to reveal Bt-tub. At all time points examined, staining for Bt tub was observed in the cell body and axons of the injected cells, and the staining was much more intense in the cell body than in the axon. Axonal staining was brightest near the cell body and declined steadily with increasing distance from the cell body. At the earliest times examined, $\sim 3$ min after injection, the Bt tub extended into the proximal part of the axon, and with increasing time after injection the tubulin was detected at progressively more distal sites. Representative examples of cells processed at 3 or 60 min after injection are shown in Figure $1, A, B, D$, and $E$, and quantitative analyses of the distribution of fliorescent staining of Bt-tub in the axons of these cells are shown in Figure $1, C$ and $F$. The front of Bt-tub is situated $\sim 105 \mu \mathrm{m}$ from the cell body by $\sim 3$ min after injection, whereas by $\sim 60$ min after injection the Bt-tub has reached the tip of the axon, a distance of $315 \mu \mathrm{m}$ from the cell body. The proximal-to-distal decine in the relative amount of Bt-tub within the axons at these times could be modeled effectively as an exponentially declining furiction (data not shown), which is consistent with the possibility that diffusion is principally responsible for the movement of the Bt-tub at these early times after injection.

Our principle goal in performing these analyses was to determine the time required for the injected tubulin to move from the injection site in the cell body to the axon tip. To determine this, we expressed the distance from the cell body to the distal-most site of Bt-tub as a percentage of total axon length. These analyses revealed that the injected tubulin reached or was very near the tips of all axons by $\sim 1$ hr after injection (Fig. 2 ). Thus, it was necessary to wait at least 1 hr after injecting the Bt-tub into the neurons to examine the incorporation of Bt-tub into MTs in the distal-most part of the axon. In practice, we found that an incubation of $2 \mathrm{hr}$ was necessary to detect Bt-tub reliably in the MT polymer in this part of the axon.

\section{Bt-tub incorporation into axonal MTs}

The appearance of Bt-tub in axonal MTs was measured at 2, 4, and $8 \mathrm{hr}$ after injection. At these times, neurons were extracted under conditions that remove unassembled tubulin, stabilize existing MTs, and cause the MT array to fray apart so that individual M'I's can be visualized (see Materials and Methods). Extracted cells were then fixed and double-stained to visualize total MTs and MTs containing Bt-tub. The absence of Bt-tub from an MT indicates that it existed in the cell at the time of Bt-tub injection and that it persisted in the cell for the entire duration of the experiment, whereas the presence of $\mathrm{Bt}$-tub in an $\mathrm{Mr}$ indicates that it assembled after injecting Bt-tub.

Figure 3 shows a low-magnification view of a cell processed $2 \mathrm{hr}$ after injection of Bt-tub. The extraction procedure has caused 


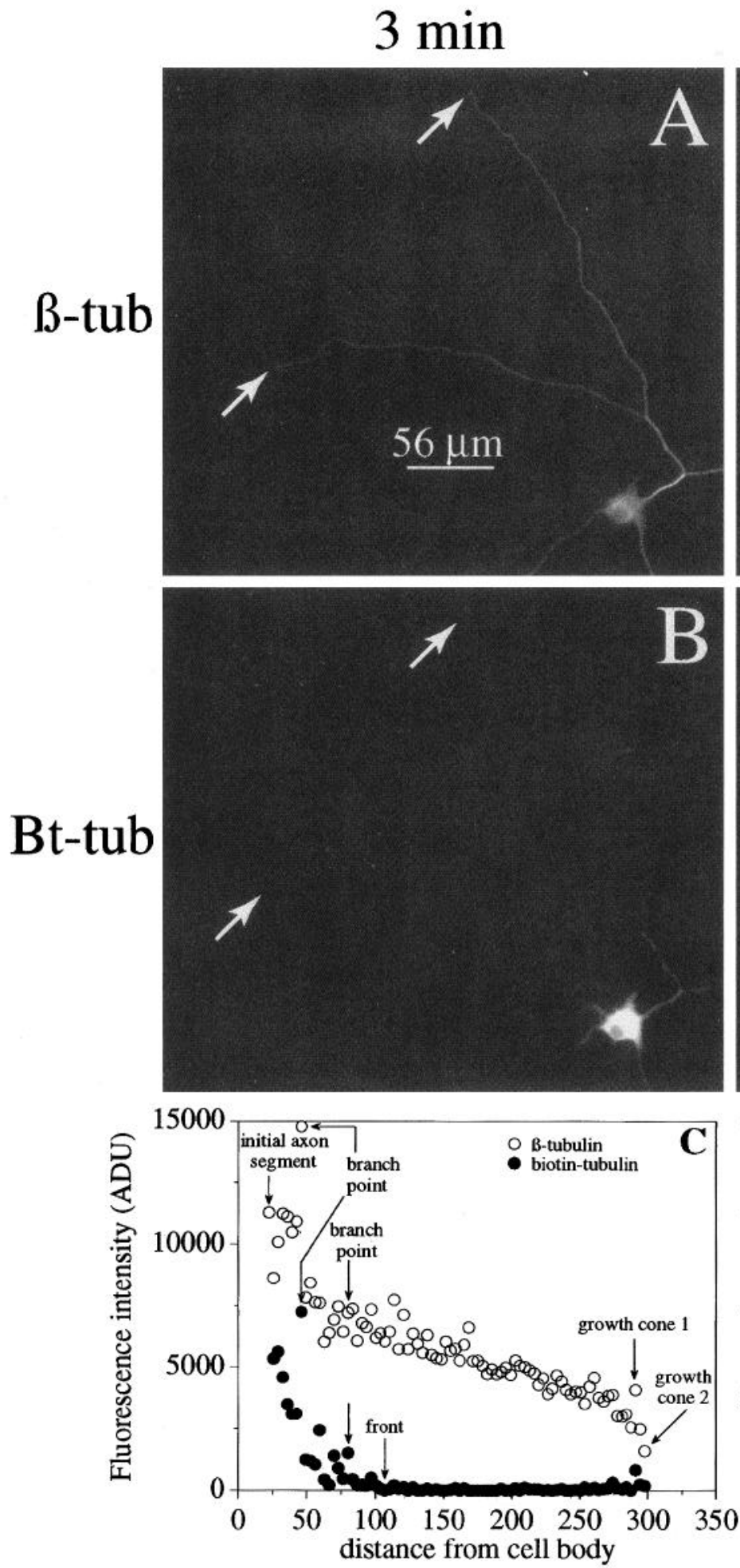

$60 \min$
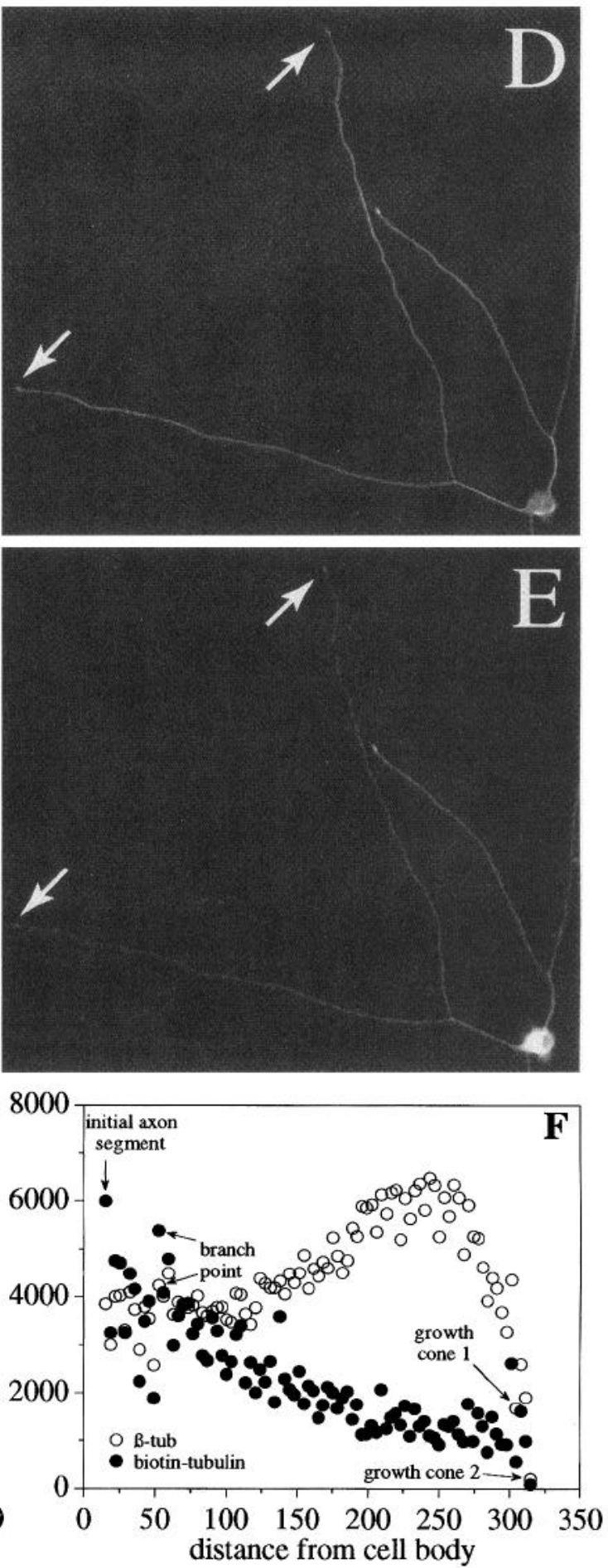

Figure 1. The distribution of Bt-tub in axons at 3 and $60 \mathrm{~min}$ after injection. Cells injected with Bt-tub (4.4 mg/ml) were fixed without extraction and then double-stained to reveal total $\beta$-tubulin and Bt-tub. $A, B, \beta$-tubulin $(\beta$-tub) and biotin-tubulin $(B t$-tub) staining, respectively, of a cell at 3 min after injection. $C$, Quantitative analysis of the distribution of $\beta$-tubulin $(O)$ and Bt-tub $(\bullet)$ staining in one axon of this cell obtained by using the segmented mask procedure (see Materials and Methods). The fluorescence intensity attributable to $\beta$-tubulin and Bt-tub in the two main branches of the parent axon was measured and then summed to create the plots shown. $D, E, \beta$-tubulin and Bt-tub staining, respectively, of a cell at 60 min after injection. $F$, Quantitative analysis of the distribution of $\beta$-tubulin and Bt-tub staining in one axon of this cell; the fluorescence intensities in both branches of the parent axon were measured and then summed to create the plots shown. The arrows in $A, B, D$, and $E$ indicate the positions of the growth cones of the analyzed axons. The upper arrows correspond to growth cone 1 indicated in the graphs, whereas the lower arrows correspond to growth cone 2 . The graphs also indicate the position of the initial axon segment and branch points. Note that the front of Bt-tub is $\sim 105 \mu \mathrm{m}$ from the cell body by 3 min after injection, whereas by $60 \mathrm{~min}$ after injection, the injected tubulin has reached the tip of the axon. 


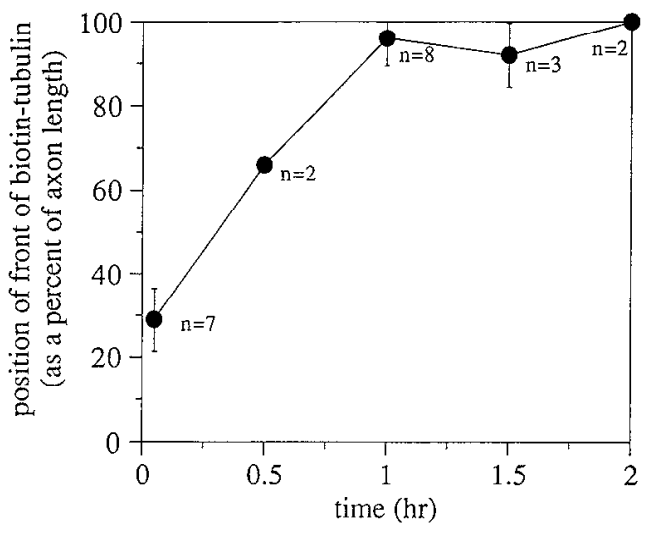

Figure 2. Position of the front of Bt-tub as a function of time after injection. The position of the front of Bt-tub in the axons of injected cells was determined from analyses like those shown in Figure 1. To generate the graph, the distance from the cell body to the front of Bt-tub then was expressed as a percentage of the total length of the axon. The data shown are mean $\pm S D$; sample size at cach time point $(\bullet)$ is indicated in the graph. Twenty-two axons were analyzed to obtain these data. The mean axon length was $323 \mu \mathrm{m}$ (range 208-508 $\mu \mathrm{m}$ ). The injected tubulin reaches the axon tip by $\sim 1 \mathrm{hr}$ after injection.

extensive fraying of the axonal M'l' array such that many M'I's can be traced for several tens of microns along their length (Fig. $3 A$ ). Figure $3 B$ shows that only a portion of the axonal MT polymer contains Bt-tub at this time. Furthermore, polymer with Bt-tub, as well as polymer without Bt-tub, was present all along the axon (Fig. $3 B$ ), and there was no indication that the proportion of polymer with or without Bt-tub varied as a function of position along the axon (but see below).

In the cells examined, regardless of the time interval between injection and analysis, most MT profiles either stained for Bt-tub all along their length or did not stain for Bt-tub at all. However, some MT profiles stained for Bt-tub over only part of their length (see arrowheads with asterisks in Figs. 3, 4). These MT profiles typically contained a single region that contained Bt-tub and a single region that did not contain Bt-tub, and the Bt-tubcontaining segment extended from the end of the segment without Bt-tub that was situated most distal relative to the cell body. Because axonal MTs in cultured sympathetic neurons are uniformly plus end-distal in polarity orientation (Baas et al., 1991), we infer that the Bt-tub-containing segment extended from the plus end of the polymer segment without Bt-tub. The direct continuity of Bt-tub-containing polymer with non-Bt-tubcontaining polymer indicates that the Bt-tub-containing segment was formed by the assembly of Bt-tub onto the ends of MTs that existed in the neuron before the injection of Bt-tub. Such assembly was observed all along the axon (see also Figs. 8-10). Comparable observations also have been obtained by Okabe and Hirokawa (1988) in studies with neurite-bearing PC12 cells.

\section{MT turnover along the axon}

The proportion of total axonal polymer that stained for Bt-tub increased progressively with time after injection. This can be seen qualitatively in Figure 4, which shows high-magnification views of axons processed at 2 and $8 \mathrm{hr}$ after injection. At $2 \mathrm{hr}$ after injection, many MT profiles did not contain Bt-tub, whereas by 8 hr after injection a vast majority of the MT profiles contained Bt-tub. Quantitative analyses of the proportion of Bt-tubcontaining polymer confirmed this impression (Fig. 5). For each cell analyzed, we measured the total length of all individual MT profiles that could be resolved in the images of total MTs. We then measured the lengths of these profiles that also stained for Bt-tub. From these two values, the proportion of MT polymer that contained Bt-tub was calculated. By $2 \mathrm{hr}$ after injection, $\sim 46 \%$ of the total polymer in the axon contained Bt-tub, and this value increased steadily with time to a value of $-96 \%$ by $8 \mathrm{hr}$ after injection. These data suggest a $t_{1 / 2}$ of $\sim 2.2 \mathrm{hr}$ for the bulk polymer in the axon.

Studies using fluorescence recovery after photobleaching (Lim et al., 1989; Edson et al., 1993) and staining for various posttranslationally modified forms of tubulin (Arregui et al., 1991; Brown et al., 1992) suggest that the turnover dynamics of MTs vary along the length of the axon, with the MT polymer in the distal part of the axon turning over more rapidly than the polymer in the proximal axon. To determine whether we could detect a similar spatial variation in our experiments, we quantified the proportion of polymer with or without Bt-tub in the proximal, middle, and distal thirds of the axon. The results are shown in Table 1. At first glance, the data suggest that there is little if any variation in the time course of appearance of Bt-tub in MTs along the length of the axon. However, it is important to realize that the lag period between the injection of Bt-tub and its arrival at different sites within the axon varies with distance from the cell body (see Figs. 1, 2). Specifically, the Bt-tub extends $50-100 \mu \mathrm{m}$ into the axon within a few minutes after injection (see Fig. 1C), whereas $\sim 1 \mathrm{hr}$ is required for the injected tubulin to reach the distal part of the axon (see Figs. $1 F, 2$ ). Thus, at each time point examined, the injected tubulin is present in the distal region of the axon for $\sim 1$ hr less than in the proximal region. Despite this, comparable proportions of polymer contain Bt-tub in both regions. On this basis, we conclude that the mechanisms responsible for the appearance of Bt-tub in MTs operate more rapidly in the distal part of the axon compared with the proximal part. These mechanisms may operate more rapidly throughout the entire distal axon. Given the limited spatial and temporal resolution of these experiments, however, it is possible also that the distal third of the axon is heterogeneous with respect to the appearance of Bt-tub in MTs and that the results obtained reflect an average of two (or more) distinct MT $t_{1 / 2}$ values, perhaps corresponding to distinct cytoplasmic domains within the distal third of the axon. In this respect, it has been reported that $t_{1 / 2}$ of the MT polymer in the growth cone is smaller on average than that in the axon shaft (Edson et al., 1993).

\section{Turnover of the tyr-tub-rich and tyr-tub-poor polymer of the axon}

We examined the time course of Bt-tub incorporation into the tyr-tub-rich and tyr-tub-poor polymer of the axon. Figure 6 shows representative images of axonal MTs from cells processed 2 or 8 hr after injection; these images show the tyr-tub-rich and tyr-tubpoor polymer of the axon as well as the polymer with Bt-tub. On average, the tyr-tub-rich polymer comprises $60 \pm 19 \%$ of the total axonal polymer. By $2 \mathrm{hr}$ after injection, Bt-tub was observed predominantly in the tyr-tub-rich polymer, and very little was detected in the tyr-tub-poor polymer. This point is illustrated particularly clearly by MT profiles showing the tyr-tub-rich and tyr-tub-poor domains of individual MTs (see the MTs indicated by arrowheads with asterisks in Fig. $6 A$ ). In such MTs, Bt-tub staining typically colocalized precisely with the tyr-tub-rich domain and was not present in the tyr-tub-poor domain. The proportion of the tyr-tub-rich and tyr-tub-poor polymer that contained Bt-tub increased with time after injection, such that by $8 \mathrm{hr}$ after injection 


\section{Total Microtubules}

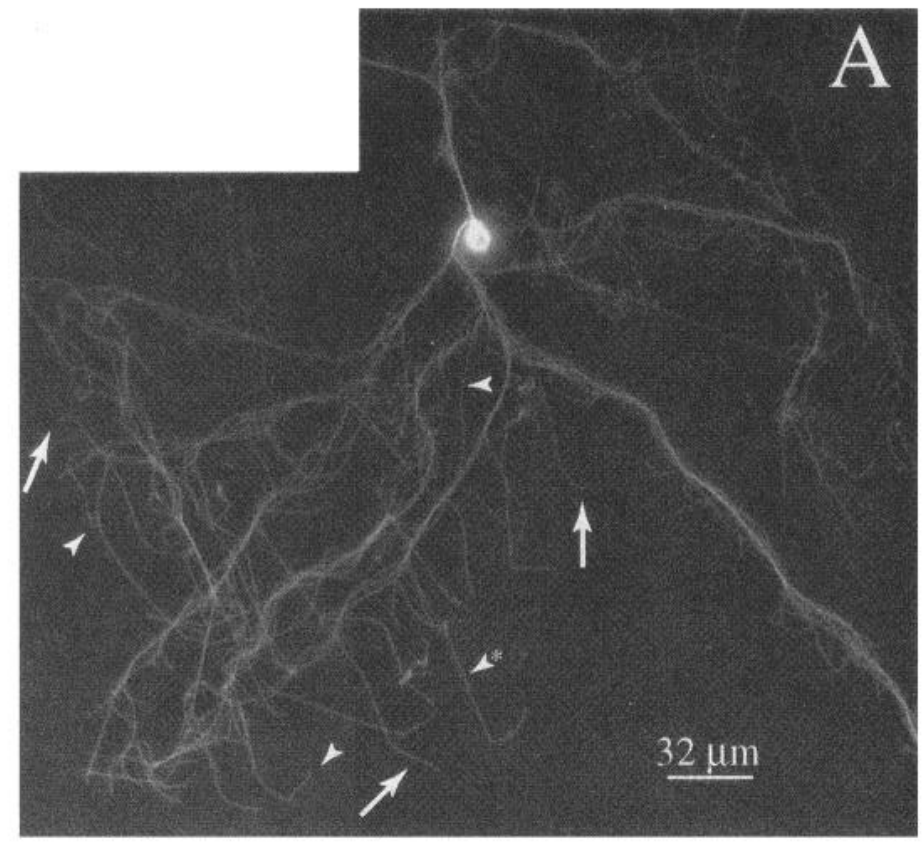

\section{Biotinylated Microtubules}

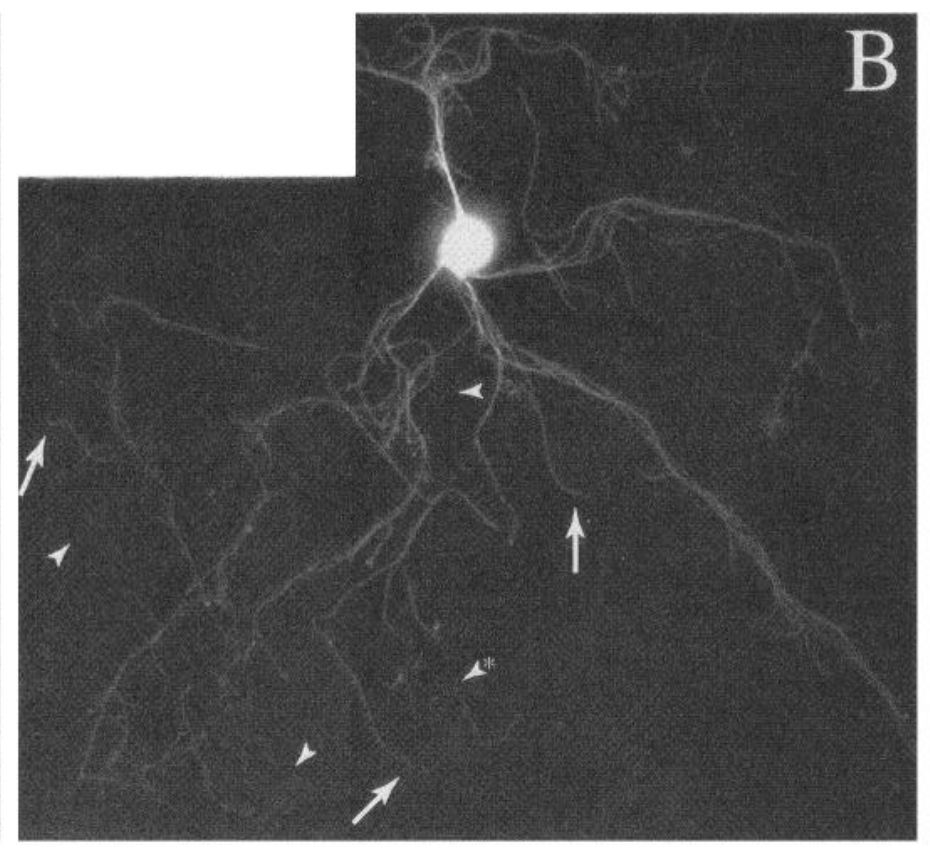

Figure 3. A low-magnification view of a neuron injected with $\mathrm{Bt}$-tub $(4.4 \mathrm{mg} / \mathrm{ml})$ and then processed $2 \mathrm{hr}$ later. $A$, Total MTs as revealed by $\beta$-tubulin staining. $B$, MTs containing Bt-tub. Examples of MTs with or without Bt-tub are indicated with arrows and arrowheads, respectively. The arrowhead with an asterisk indicates an MT that contains Bt-tub over only part of its length. At $2 \mathrm{hr}$ after injection, a minority of the total MT polymer of the axon contain Bt-tub, and MTs with or without Bt-tub can be seen all along the axon.

all of the tyr-tub-rich polymer and a vast majority of the tyr-tubpoor polymer contained Bt-tub (see Fig. 6). In this respect, by $8 \mathrm{hr}$ after injection we observed typically that the tyr-tub-rich and tyr-tub poor domains of individual MTs both contained Bt-tub (see MT profiles indicated by arrowheads with asterisks in Fig. $6 C, D)$. Quantitative analysis confirmed that Bt-tub appeared in the tyr-tub-rich polymer distinctly faster than in the tyr-tub-poor polymer (Fig. 7). For example, by $2 \mathrm{hr}$ after injection, $\sim 75 \%$ of the tyr-tub-rich polymer of the axon contained Bt-tub, whereas only $\sim 10 \%$ of the tyr-tub-poor polymer contained Bt-tub. By $8 \mathrm{hr}$ after injection, $\geq 95 \%$ of both types of polymer contained Bt-tub. $\mathrm{Bt}$-tub incorporation into the bulk tyr-tub-rich and tyr-tub-poor polymer of the axon occurred with a $t_{1 / 2}$ of $\sim 1.3$ and $3.3 \mathrm{hr}$, respectively.

\section{Long-lived polymer of the axon: abundance, distribution, and assembly competence}

The data on the appearance of Bt-tub in axonal MTs indicate that in rat sympathetic neurons cultured for $\sim 1 \mathrm{~d}$, very little $(\leq 4 \%)$ of the MT polymer in the axon persists for $>8 \mathrm{hr}$ (see Figs. 4, 5). Although the fraying procedure allows us to trace many MTs over substantial portions of their length (see Figs. 3, 4, 6) (Brown et al., 1993), the degree of fraying is not sufficient to trace all axonal MTs over their entire length. Thus, it is possible that the above analyses underestimate the relative abundance of the polymer in the axon that persists for relatively long times. For this reason, to study this long-lived polymer we have used an alternative procedure that is independent of the extent of fraying. Specifically, neurons were microinjected with Bt-tub and then processed using the Ab-blocking technique described by Schulze and Kirschner (1987). In this procedure, fixed cells first are incubated with a rabbit anti-biotin $\mathrm{Ab}$ followed by four sequential incubations with secondary Abs. These secondary Abs form a dense coat on the MTs containing Bt-tub, which prevents additional Abs from gaining access to these MTs. Thus, the MTs with Bt-tub are blocked from staining by additional Abs against tubulin, whereas the MTs without Bt-tub can be stained by such Abs. These latter MTs, which have persisted for the entire duration of the experiment, are referred to as unblocked MTs, and they are selectively stained with a mouse anti- $\beta$-tubulin $\mathrm{Ab}$ and appropriate secondary Abs. This procedure permits the polymer without Bt-tub to be visualized easily and separately from the polymer with Bt-tub.

Figures 8 and 9 show low-magnification views of neurons injected with Bt-tub and then processed $8 \mathrm{hr}$ later according to the Ab-blocking procedure. In regions of the axon in which the MTs are well separated from each other, the staining for Bt-tub is exactly complementary to that for $\beta$-tubulin. For example, in the region outlined in Figure 8 (dashed lines), the MT indicated (arrow) stains strongly for Bt-tub but not for $\beta$-tubulin, whereas another MT indicated (arrowhead) stains for $\beta$-tubulin but not for Bt-tub (this same region is shown at higher magnification in Fig. $10)$. Such observations indicate that the procedure is working as expected and, therefore, that bright staining for $\beta$-tubulin is a reliable marker for MTs that have not incorporated Bt-tub during the time course of the experiment. Furthermore, inspection of Figures 8 and 9 shows that the MTs without Bt-tub (i.e., the unblocked MTs) can be detected readily in well frayed regions of the axon and in regions that are not well frayed.

At $8 \mathrm{hr}$ after injection, MT polymer without Bt-tub is observed in both the cell body and the axon. This unblocked polymer constitutes a minor subset of the total polymer in the axon (see Figs. 8, 9). Although we cannot quantify the relative proportions of polymer with or without Bt-tub in the axon, the results are 


\section{Total MT}
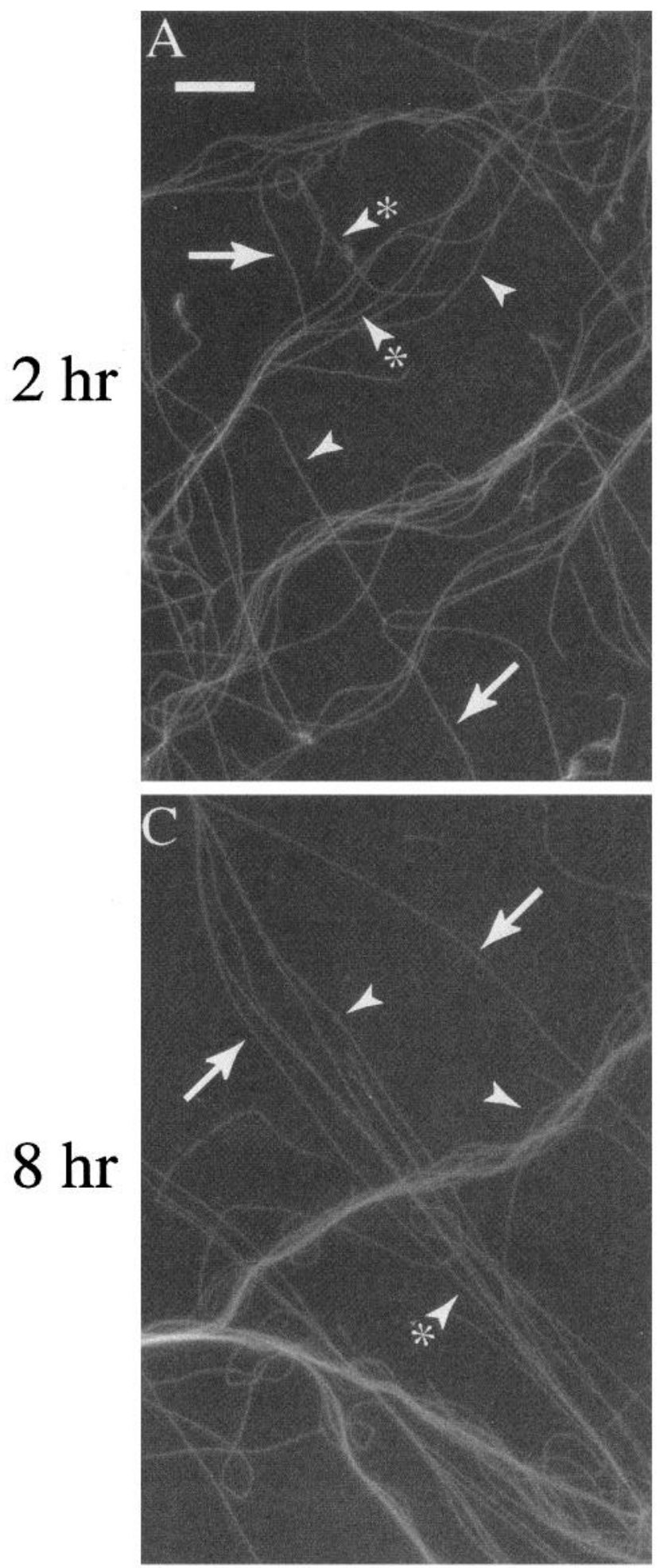

\section{Biotinylated MT}
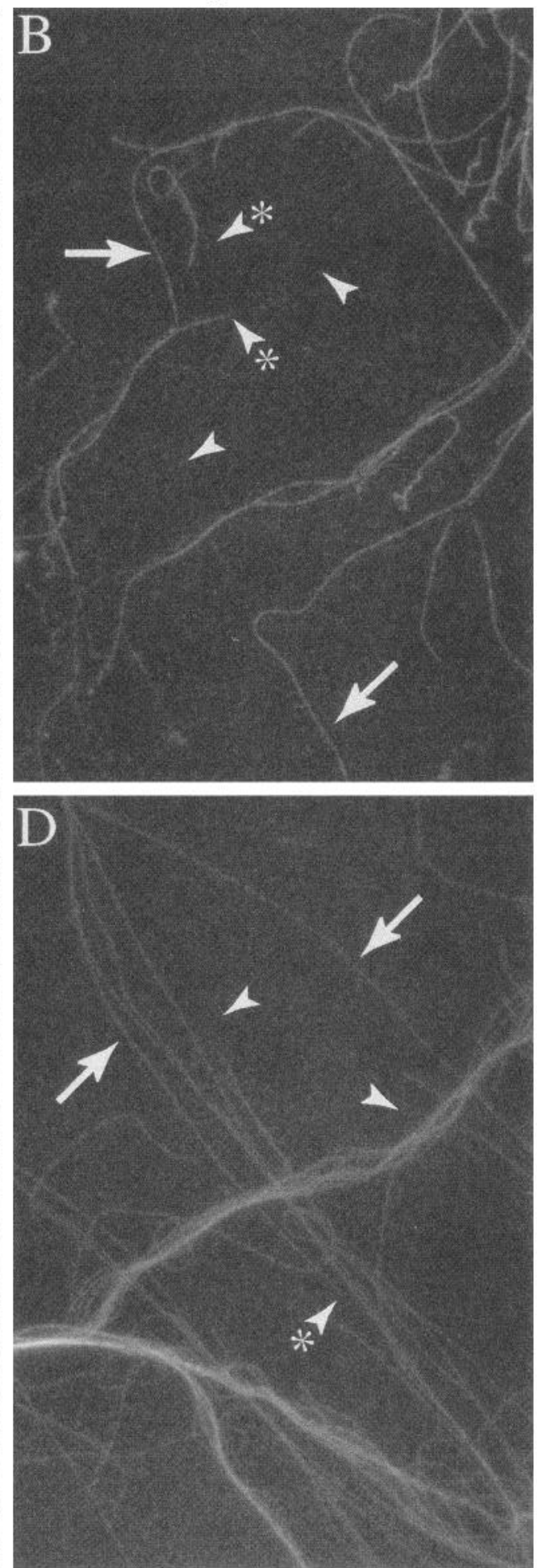

Figure 4. High-magnification views of Bt-tub incorporation into axonal MTs at $2 \mathrm{hr}(A, B)$ and $8 \mathrm{hr}(C, D)$ after injection. $A, C$, Total MTs as revealed by $\beta$-tubulin staining. $B, D$, MTs containing Bt-tub. Examples of MTs with or without Bt-tub are indicated by arrows and arrowheads, respectively. The arrowheads with asterisks indicate MT profiles that contain Bt-tub over only part of their length; the tip of the arrowhead points to the transition between the portions of the polymer with or without Bt-tub. At $2 \mathrm{hr}$ after injection, the majority of the MT polymer does not contain Bt-tub, whereas by $8 \mathrm{hr}$ after injection the vast majority of the polymer contains Bt-tub. Scale bar, $13 \mu \mathrm{m}$. 


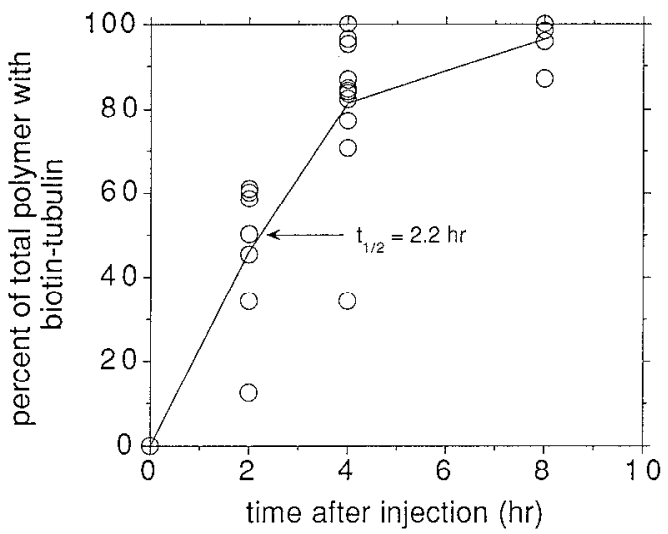

Figure 5. Quantitative analysis of the proportion of axonal MT polymer with Bt-tub at varying times after injection. For each cell analyzed, we measured the total length of all profiles of individual MT that could be resolved in the images of total MTs. We then measured the lengths of these profiles that also stained for Bt-tub. From these two values, the proportion of MT polymer that contained Bt-tub was calculated. These analyses show that the proportion of total polymer with Bt-tub increases steadily with time, such that by $8 \mathrm{hr}$ after injection $\sim 96 \%$ of the axonal polymer contains Bt-tub. The appearance of Bt-tub in the bulk polymer of the axon occurs with a $t_{1 / 2}$ of $\sim 2.2 \mathrm{hr}(\mathrm{O})$.

Table 1. MT turnover in proximal, middle, and distal regions of the axon

Proportion of polymer containing Bt-tub

\begin{tabular}{llll} 
& \multicolumn{2}{l}{ Region of axon } \\
\cline { 2 - 4 } Time $($ hr $)$ & Proximal & Middle & Distal \\
\hline 2 & $44 \pm 19$ & $48 \pm 15$ & $45 \pm 18$ \\
4 & $90 \pm 11$ & $79 \pm 17$ & $85 \pm 12$ \\
8 & 90 & $75 \pm 27$ & $99 \pm 2$
\end{tabular}

Incorporation of Bt-tub into MTs in different regions of the axon, Each axon was divided into proximal, middle, and distal thirds, and the proportion of MT polymer in each region that contained Bt-tub was determined. Data shown are mean $\pm \mathrm{SD}$; $n=5,7$, and 3 axons for the 2,4 , and $8 \mathrm{hr}$ time points, respectively, except for the proximal data point at $8 \mathrm{hr}$, which is based on one axon because only one axon showed adequate fraying in its proximal region.

entirely consistent with the conclusion from the quantitative analyses (see Fig. 5): that only a small percentage of the total MT polymer in the axon persists for $8 \mathrm{hr}$ or longer. At $8 \mathrm{hr}$ after injection, the polymer without Bt-tub is located predominantly in the proximal half of the axon, although MT profiles without Bt-tub ean be detected more distally as well (Figs. 8, 9). However, we have not detected any unblocked polymer in the region of the growth cone or in the portion of the axon immediately contiguous with the growth cone at $8 \mathrm{hr}$ after injection.

The polymer without Bt-tub shows a wide spectrum of lengths, ranging from a few microns to several tens of microns (Figs. 8, 9).
Furthermore, in well frayed regions, this polymer was observed frequently as part of longer MTs that contained Bt-tub over only part of their length (see Fig. 10). The Bt-tub-containing segment typically extended from the plus end of the segment without Bt-tub. These observations unequivocally show that the "older" polymer in the axon is assembly-competent at its plus end and that it nucleates assembly locally within the axon.

Even in well frayed preparations, we typically were able to visualize only one end of an MT, and this usually was the end situated distal to the cell body, i.e., the plus end. Occasionally, we observed the end situated proximal to the cell body (Figs. 8, 9, double arrowheads), which we presume is the minus end of the MT. By 8 hr after injection, some MTs contained Bt-tub at their minus end (Fig. 8), whereas others did not (Fig. 9). In all but one case, there was no evidence for assembly of Bt-tub from the minus ends of MT profiles without Bt-tub. The one exception was a short MT profile without Bt-tub that had Bt-tub-containing polymer extending from both of its ends (see inset in Fig. 9C). Such images suggest that assembly can occur from the minus ends as well as from the plus ends of MTs in the axon. However, the extent to which this actually occurs is unclear because it is rare that we see the minus end of polymer segments without Bt-tub, and it is rarer still that these ends are contiguous with a polymer segment with Bt-tub.

Finally, we also performed Ab-blocking analyses on neurons incubated for $20 \mathrm{hr}$ after injection. In each of three injected axons, MTs stained strongly for Bt-tub in the cell body and all along the axon, from the most proximal region all the way to the tip. Two of these axons contained no unblocked polymer (i.e., polymer that stained for $\beta$-tubulin and thus did not contain Bt-tub). One axon contained two MT profiles that were unblocked; these unblocked MT profiles were situated within the distal half of the axon. Thus, during the $20 \mathrm{hr}$ of incubation with Bt-tub, all or almost all of the polymer present in the axon at the time of injection was replaced with new polymer that contained Bt-tub.

\section{DISCUSSION}

We have microinjected Bt-tub into cultured neurons to explore the sites of MT assembly and the stability of MTs in actively growing axons. A novel aspect of this work involves the use of the frayed preparation, which permits visualization of individual axonal MTs over substantial portions of their length. Thus, we could evaluate the dynamic behavior of individual MTs as well as the MT population as a whole. Our results show that MT assembly occurs all along the length of the axon and that this is manifest principally by the addition of Bt-tub to the plus ends of MTs. Bt-tub appeared in the MT population of the axon with an overall $t_{1 / 2}$ of $\sim 2.2 \mathrm{hr}$. This reflected an average of two distinct components that corresponded to the tyr-tub-rich and tyr-tub-poor polymer, which had an apparent $t_{1 / 2}$ of $\sim 1.3$ and $3.3 \mathrm{hr}$, respectively. We discuss these findings in terms of the generation of the MT array during axon growth.

Figure 6. Bt-tub in the tyr-tub-rich (Tyr-rich) and tyr-tub-poor (Tyr-poor) polymer of the axon at 2 and 8 hr after injection. Tyr-tub-rich and tyr-tub-poor polymer $(A, B)$ were revealed by staining with an Ab specific for tyr-tub (see Materials and Methods). With the staining conditions used, tyr-tub-rich polymer stains brightly, whereas by comparison the tyr-tub-poor polymer is much dimmer. Bt-tub staining is shown in $C$ and $D$. Tyr-tub-rich polymer is shown with arrows with single and double arrowheads; the arrows with single arrowheads identify examples of tyr-tub-rich polymer with Bt-tub, whereas arrows with double arrowheads identify examples of tyr-tub-rich polymer without Bt-tub (these were seen only at $2 \mathrm{hr}$ after injection). The arrowheads identify tyr-tub-poor polymer. At $2 \mathrm{hr}$ after injection, very little $(\sim 10 \%)$ of the tyr-tub-poor polymer contains Bt-tub (see text). By 8 hr after injection, the vast majority of the tyr-tub-poor polymer contains Bt-tub. The arrowheads with asterisks identify the transition between the tyr-tub-rich and tyr-tub-poor domains along individual axonal MTs. At $2 \mathrm{hr}$ after injection, Bt-tub staining coincides precisely with the tyr-tub-rich domain and is absent from the tyr-tub-poor domain. By $8 \mathrm{hr}$ after injection, Bt-tub staining spans both domains. 


\section{Tyr-rich + Tyr-poor Microtubules}
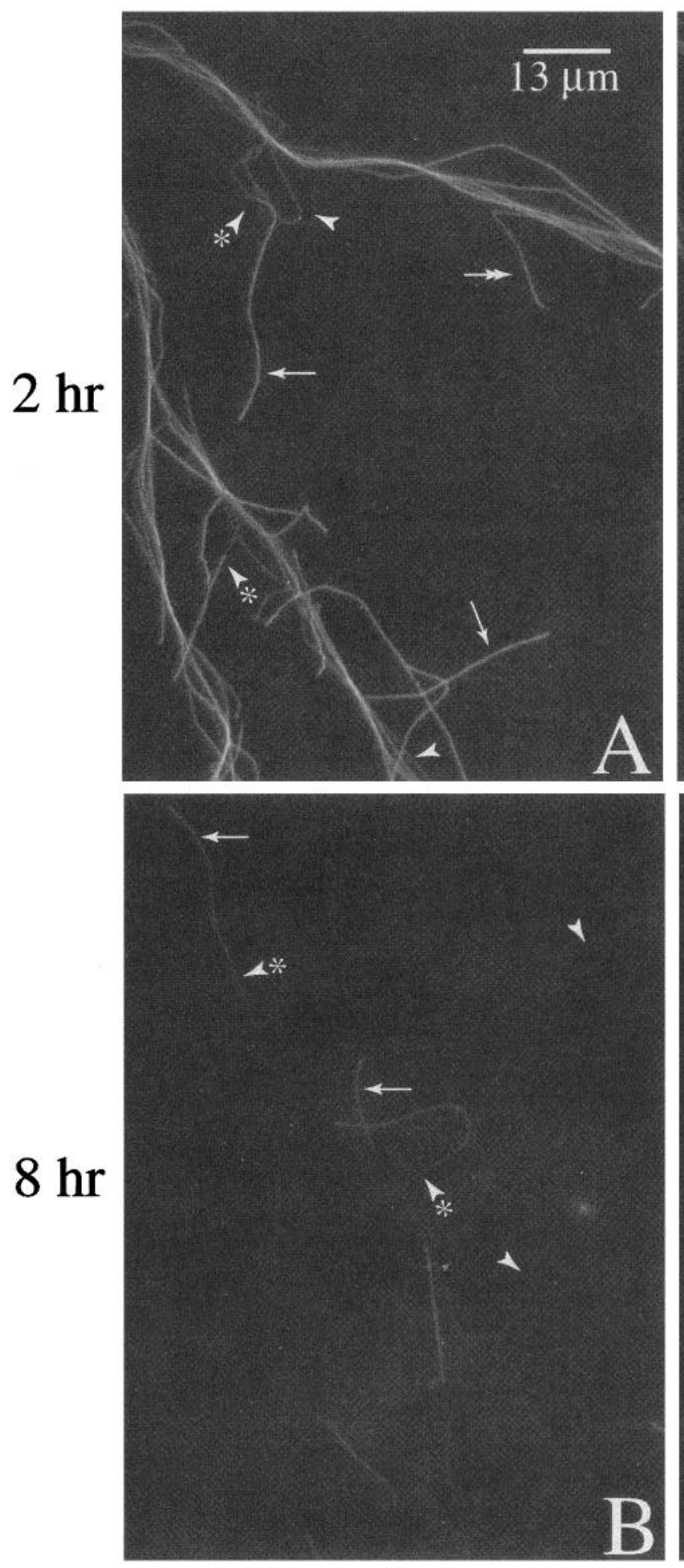

Biotinylated Microtubules
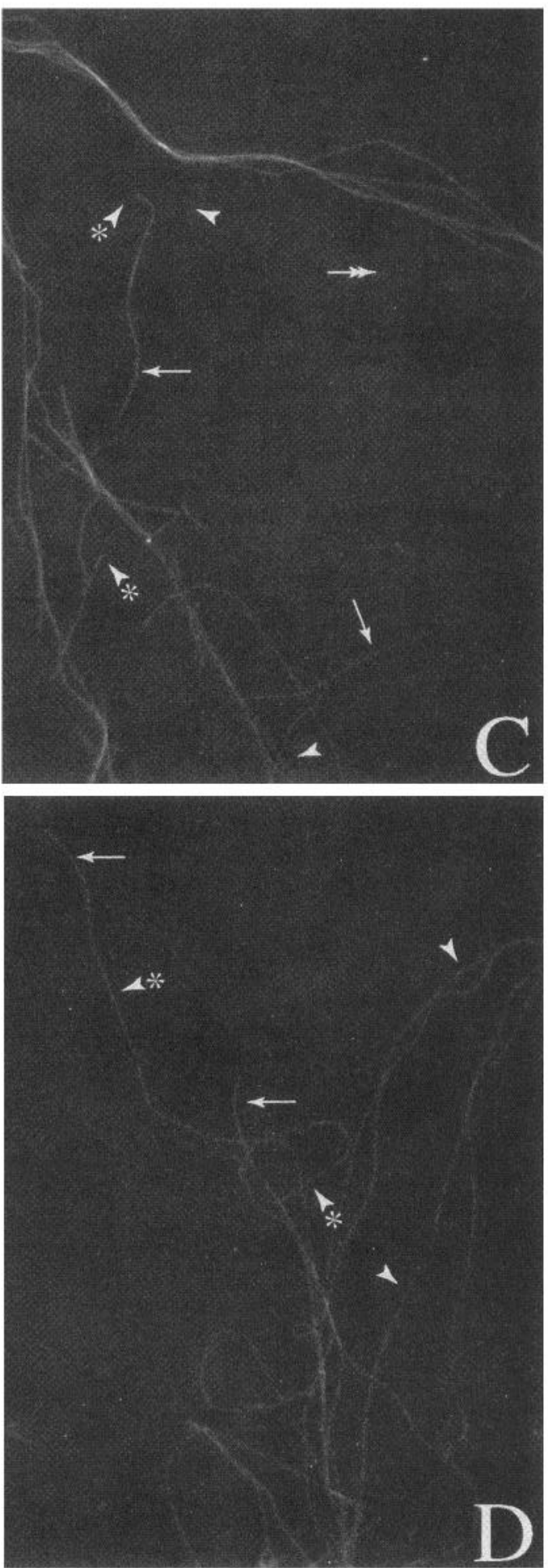


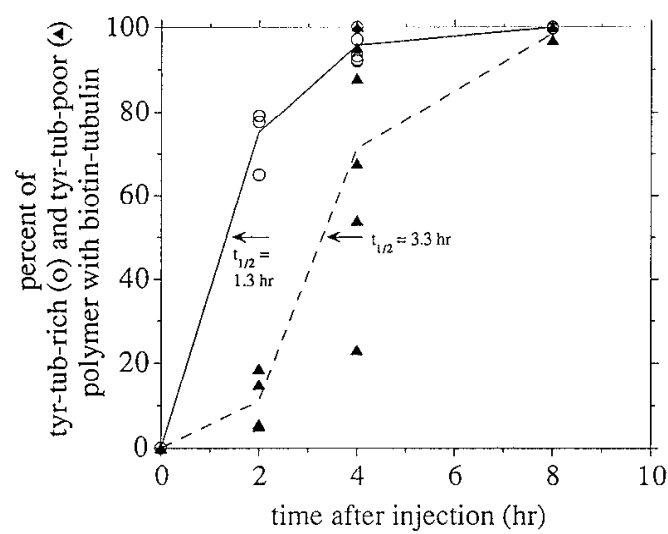

Figure 7. Quantitative analysis of the proportion of tyr-tub-rich $(O)$ and tyr-tub-poor (A) MT polymer with Bt-tub at varying time points after injection. For each cell analyzed, we measured the total length of tyr-tubrich and tyr-tub-poor profiles that could be resolved in the images of total MTs. We then measured the lengths of these profiles that also stained for Bt-tub. From these two values, the proportion of tyr-tub-rich and tyr-tubpoor polymer that contained Bt-tub was calculated. These analyses show that the proportion of tyr-tub-rich and tyr-tub-poor polymer with Bt-tub increases steadily with time after injection, and that Bt-tub appears in tyr-tub-rich polymer more rapidly than in tyr-tub-poor polymer. We note that the $4 \mathrm{hr}$ data for tyr-tub-poor polymer exhibit considerable variability. The basis for this is not known; it does not appear to correlate with any parameters considered, including time in culture or axon length. The overall time course of Bt-tub appearance in the bulk tyr-tub-rich and tyr-tub-poor polymer occurred with $t_{1 / 2}$ values of 1.3 and $3.3 \mathrm{hr}$, respectively.

When considering the present data, it is important to note that the injection of tubulin acutely alters the normal balance of asscmbled and unasscmbled tubulin within the neuron as well as the normal balance between tubulin and MT-associated proteins. To minimize the potential effects of these alterations on the parameters of MT turnover examined in the present studies, we attempted to inject tracer amounts of Bt-tub. The following observations suggest that the amount of Bt-tub injected into the neurons represents a minority relative to the endogenous tubulin. First, detection of Bt-tub in axonal MTs absolutely required the use of two fluorescent secondary Abs, as described in Materials and Methods. Second, Bt-tub staining of MTs typically appeared patchy (Figs. 3, 4, 6) rather than uniform, as is the case for $\beta$-tubulin staining. Third, in the Ab-blocking procedure used to distinguish MTs with Bt-tub from MTs without Bt-tub (Figs. 8-10), it has been estimated that a molar ratio of $\sim 1$ Bt-tub to 10 unmodified tubulin in MTs is required to obtain blocking (Schulze and Kirschner, 1987). This minimum was achieved by injecting Bt-tub at a concentration of $32 \mathrm{mg} / \mathrm{ml}$. For the quantitative analyses (Figs. $5,7)$, Bt-tub was used at $4.4 \mathrm{mg} / \mathrm{ml}$. Although this concentration of Bt-tub worked well for these analyses, it was not sufficient to permit Ab blocking (data not shown). Thus, we can infer that under these conditions Bt-tub accounts for $<10 \%$ of the tubulin in MTs that contain Bt-tub. Assuming that the ratio of Bt-tub to unmodified tubulin in MTs containing Bt-tub is reflective of that in the unassembled pool, then these considerations indicate that the size of the tubulin pools was affected only modestly by injection of Bt-tub and, therefore, that the assembly and turnover behavior of MTs in injected cells should approximate reasonably the assembly and turnover behavior in noninjected cells.
We showed previously that axonal MTs are composite structures consisting of two distinct domains that differ dramatically in their relative amount of tyr-tub (Baas and Black, 1990). One domain is relatively tyr-tub-poor and is situated at the minus end of the MT, whereas the other domain is tyr-tub-rich and extends from the plus end of the tyr-tub-poor domain to the end of the MT. These two domains also differ dramatically in their content of acetylated $\alpha$-tubulin and in their sensitivity to drugs that promote MT depolymerization (Baas and Black, 1990; Brown et al., 1993). The present studies extend these observations by showing that these two domains also differ in their dynamic properties. This is seen in analyses of the bulk tyr-tub-rich and tyr-tub-poor polymer of the axon, which reveal a two- to threefold difference in the turnover of these two types of polymer (Fig. 7). Furthermore, observations on individual MTs at short times after injection fully support and extend this view. Specifically, in MT profiles that contain the transition between the tyr-tub-rich and tyr-tub-poor domains, Bt-tub typically colocalized precisely with the tyr-tubrich domain and is not present in the tyr-tub-poor domain (Fig. $6 A, B)$. The absence of Bt-tub from the tyr-tub-poor domains indicates that these domains existed in the cell at the time of Bt-tub injection and persisted for the entire duration of the experiment. Conversely, the presence of Bt-tub in the tyr-tub-rich dundins indicates that these domains formed after injection of Bt-tub. Thus, for these MTs we can conclude unequivocally that the tyr-tub-rich domain is younger than the tyr-tub-poor domain. Furthermore, the observation at $2 \mathrm{hr}$ after injection that staining of the tyr-tub-rich domain for Bt-tub typically began precisely at its origin from the tyr-tub-poor domain (Fig. 6) indicates that the tyr-tub-poor polymer is assembly-competent and nucleates the assembly of tyr-tub-rich polymer locally within the axon.

The significance of stable MTs in axons has been discussed in terms of organizing MT assembly within the axon (for review, see Joshi and Baas, 1993; Black, 1994). Although tubulin can selfassemble into new MTs under in vitro conditions, such selfassembly occurs to a limited extent, if at all (Kirschner and Mitchison, 1986), in cells. Instead, discrete MT templates such as the centrosome direct the assembly of tubulin (Brinkley, 1985). A hallmark of MT-nucleating structures is that they produce MT arrays of uniform polarity orientation (Brinkley, 1985). Although axonal MTs are uniform in polarity orientation (Burton and Paige, 1981; Heidemann et al., 1984), axons lack traditional MTnucleating structures. Furthermore, axonal MTs start and stop within the axon itself and, thus, lack continuity with MTnucleating structures in the cell body (Bray and Bunge, 1981; Tsukita and Ishikawa, 1981; Stevens et al., 1988; Yu and Baas, 1994). Nonetheless, MT assembly is active in growing axons (Lim et al., 1990; Okabe and Hirokawa, 1990) (present results), and this assembly preserves the plus end-distal orientation of axonal MTs. To account for this, it has been suggested that axons contain stable MTs that serve as templates for nucleating tubulin assembly (Black et al., 1984; Heidemann et al., 1984; Morris and Lasek, 1984; Sahenk and Brady, 1987). These stable MTs have a plus end-distal orientation, and new polymer assembled from them will have the same polarity orientation. These stable MTs thus provide the structural basis for the active tubulin assembly that occurs in growing axons and for maintaining the uniform, plus end-distal polarity orientation of the polymer formed in the axon. The present results show that the tyr-tub-poor polymer of the axon has the stability and assembly competence to serve such functions.

The MTs in the axons studied in the present experiments exhibited an average $t_{1 / 2}$ of $\sim 2.2 \mathrm{hr}$. This is much longer than that 


\section{Microtubules without biotin-tubulin}

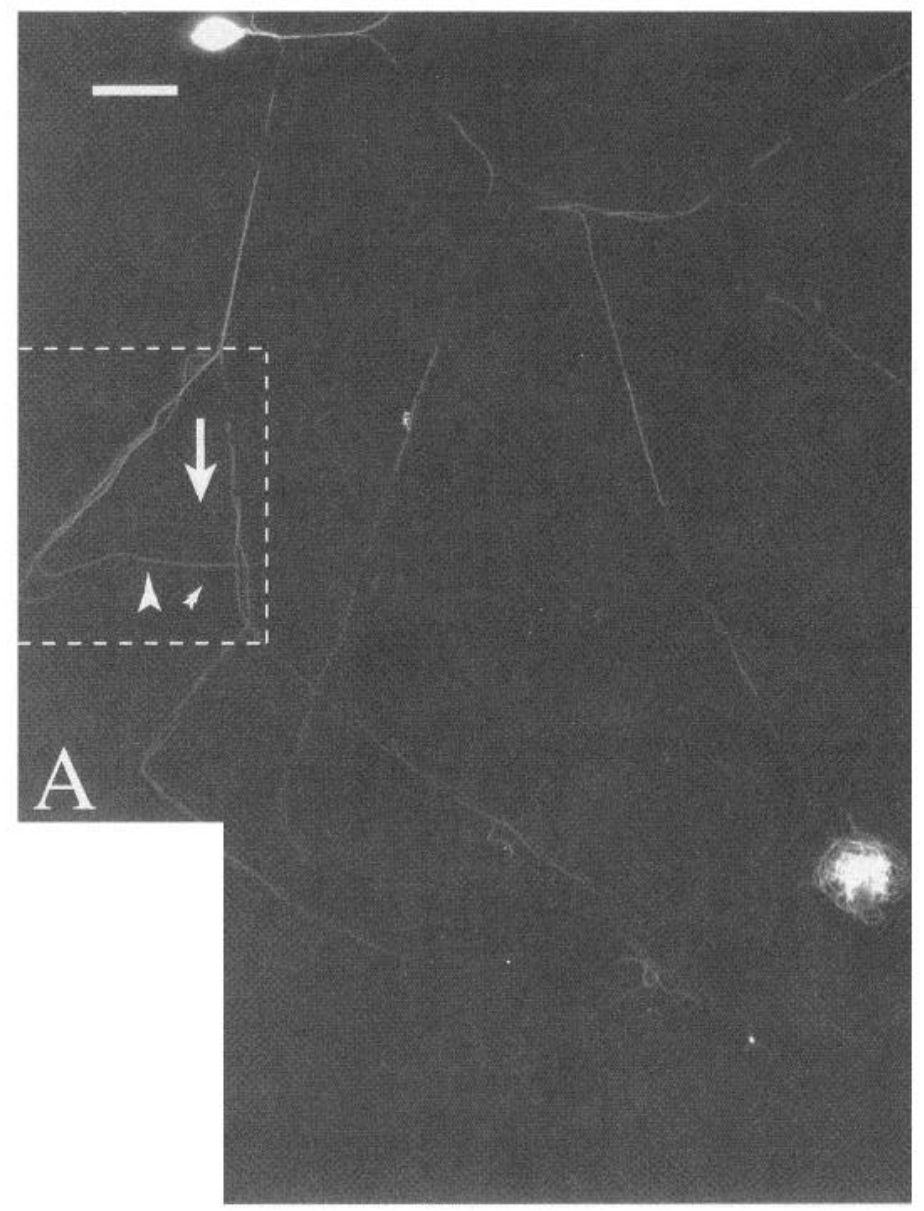

\section{Microtubules with} biotin-tubulin

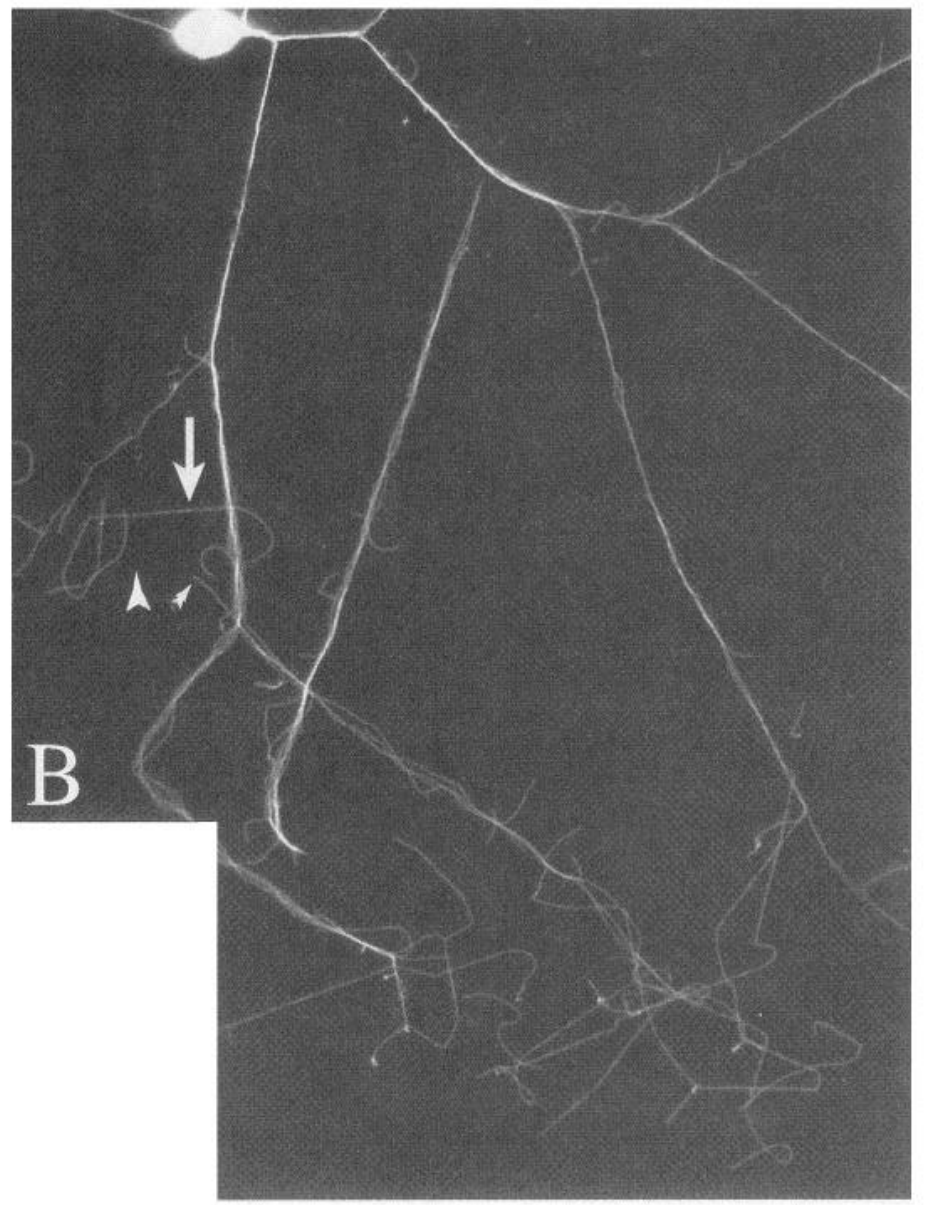

Figure 8. Visualization of long-lived MT polymer in growing axons using the Ab-blocking technique. The cell was injected with Bt-tub (32 mg/ml) and then processed $8 \mathrm{hr}$ later to reveal MT polymer with or without Bt-tub, according to the Ab-blocking procedure as described in Materials and Methods. MT polymer without Bt-tub, i.e., polymer that stains for $\beta$-tubulin but not for $\mathrm{Bt}$-tub, is shown in $A$, whereas the polymer with $\mathrm{Bt}$-tub, i.e., polymer that stains for Bt-tub but not for $\beta$-tubulin, is shown in $B$. A portion of the hatched region in $A$ is shown at higher magnification in Figure 10. This region is relatively well frayed and shows that the staining patterns for $\beta$-tubulin and Bt-tub are exactly complementary to each other. Specifically, the MT identified by the arrow stains for Bt-tub but not for $\beta$-tubulin, whereas the converse is true for the MT identified by the arrowhead. The double arrowhead identifies the minus end of an MT that contains Bt-tub at its minus end. Note also the non-neuronal cell present in $A$. Scale bar, $32 \mu \mathrm{m}$.

reported for fibroblast and epithelial cells, by a factor of $10-100$ depending on the specific cell type and stage of the cell cycle studied (Salmon et al., 1984; Cassimeris et al., 1986, 1988; Geuens et al., 1989; Pepperkok et al., 1990; Sheldon and Wadsworth, 1993). One potential consequence of these cell type-specific differences in MT dynamics is a corresponding difference in MT length. Axonal MTs are much longer on average than those in other cell types. For example, we frequently encounter MT profiles that are $50-100 \mu \mathrm{m}$ in length, and MTs in excess of $200 \mu \mathrm{m}$ are not uncommon (also see Bray and Bunge, 1981; Brown et al., 1993), and similar or even greater lengths have been seen in other types of neurons using serial reconstruction analyses (Tsukita and Ishikawa, 1981). By contrast, lengths of $20-30 \mu \mathrm{m}$ are long for many fibroblastic and epithelial cells. The relatively long length of axonal MTs is a natural consequence of their relatively long $t_{1 / 2}$ (and a steady supply of subunits). The functional significance of long MTs is unknown. It has been shown that neurons can extend axons under experimental conditions that result in only short MTs (average length $1.6 \mu \mathrm{m}$ ); however, the axons remain short (Baas and Ahmad, 1993). Thus, long MTs may be necessary for growing long axons.

Although the discussion thus far has emphasized the unusual stability of axonal MTs, it is noteworthy that we did not detect any polymer that persisted as long as the axon itself. This point is revealed especially clearly in the experiments using the Abblocking procedure to visualize long-lived polymer. In all axons studied, little polymer persists for $>8 \mathrm{hr}$ (Figs. 8, 9), and in most axons none persisted for $>20 \mathrm{hr}$. Thus, during a period of several hours most or all MTs in the axon depolymerize entirely and are replaced with new polymer. Similar conclusions also were proposed on the basis of studies examining the behavior of the MT population as a whole in growing axons (Lim et al., 1990; Okabe 


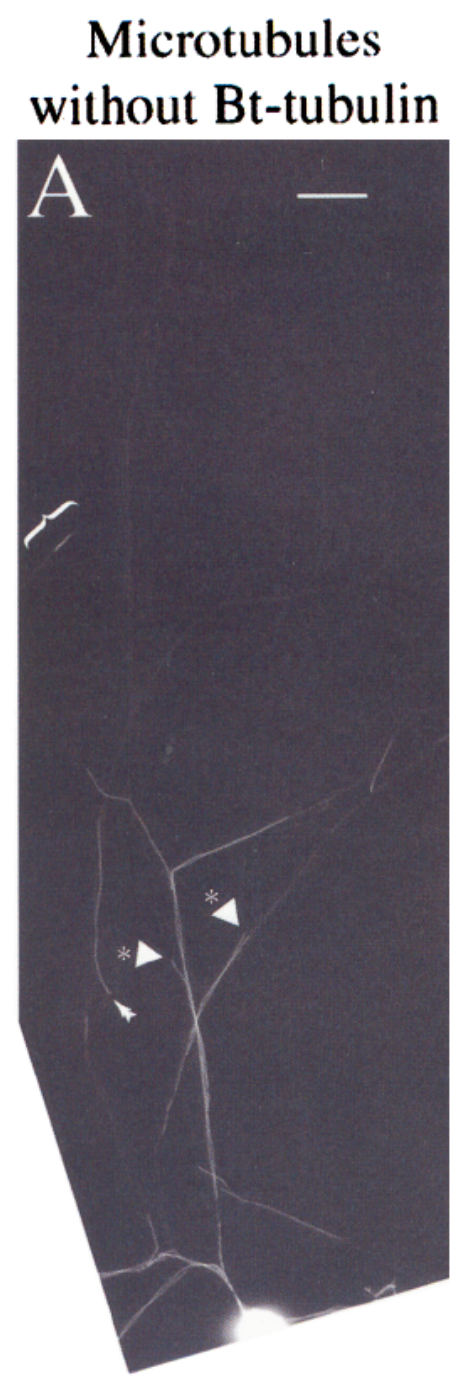

\section{Microtubules with Bt-tubulin}
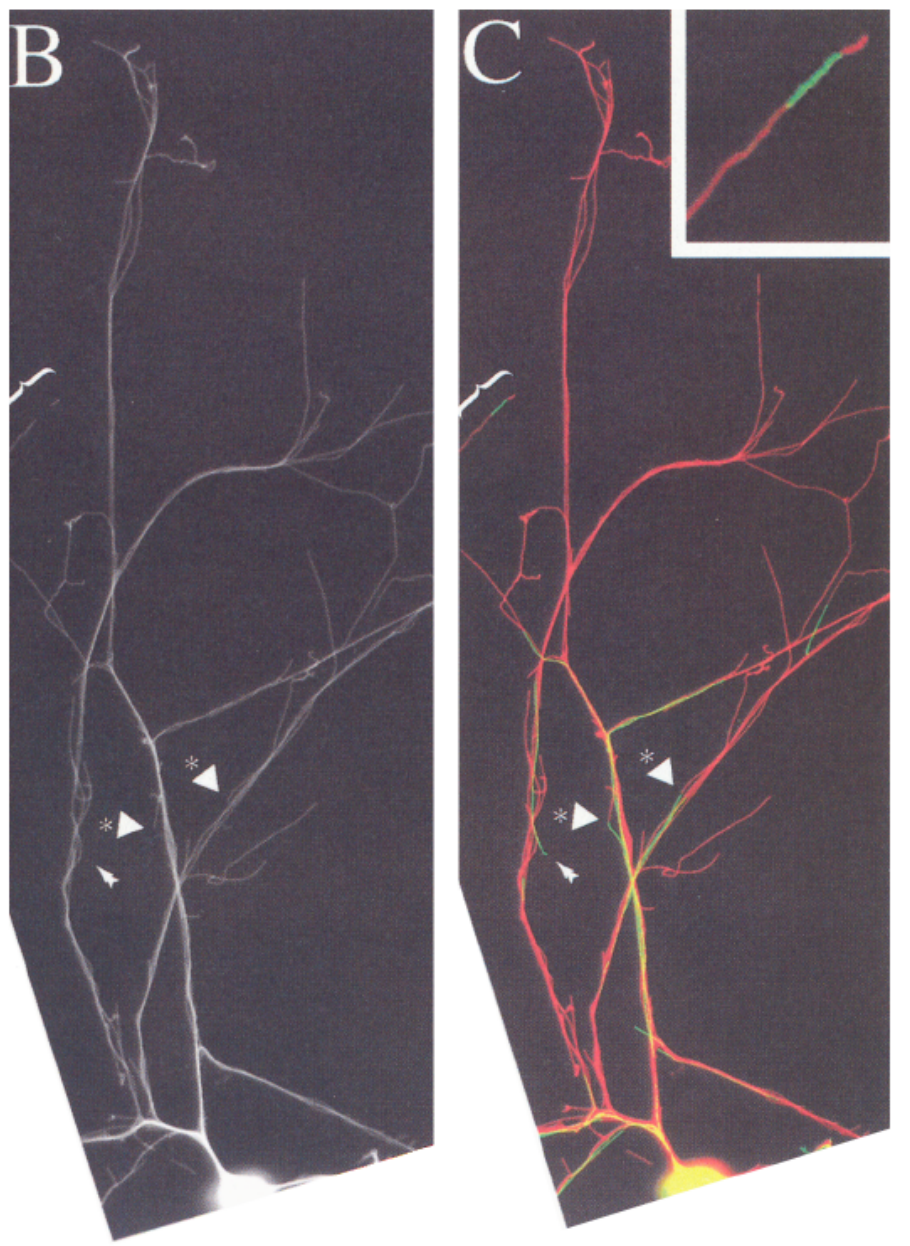

Figure 9. Distribution of MT polymer with and without Bt-tub at $8 \mathrm{hr}$ after injection using the Ab-blocking procedure. This figure shows another cell processed according to the Ab-blocking procedure. MT polymer without Bt-tub, i.e., polymer that stains for $\beta$-tubulin but not for Bt-tub, is shown in $A$, whereas the polymer with Bt-tub, i.e., polymer that stains for Bt-tub but not for $\beta$-tubulin, is shown in $B$. $C$, Multicolor overlay in which the polymer without Bt-tub is depicted in green and the polymer with Bt-tub is depicted in red. The arrowheads with asterisks point to individual MTs that contain Bt-tub only over part of their length; the tip of each arrowhead points to the transition between the portion of the polymer with Bt-tub and the portion without $\mathrm{Bt}$-tub. The double arrowhead identifies the minus end of an MT that does not contain Bt-tub at its minus end. The brace identifies a short polymer segment that is enlarged in the inset. This polymer segment contains a short length without Bt-tub. Both ends of this segment without Bt-tub are contiguous with polymer with Bt-tub. Scale bar, $32 \mu \mathrm{m}$.

\section{Microtubules without Bt-tubulin}

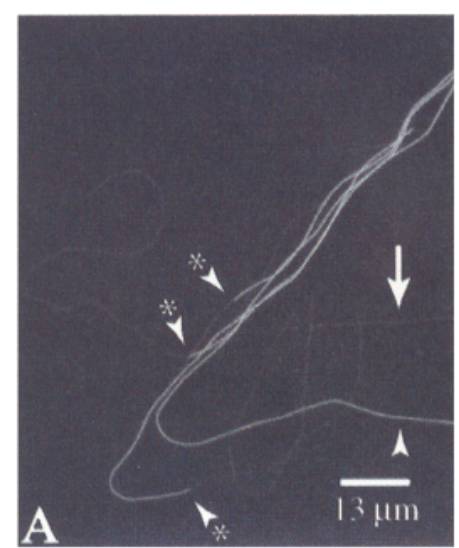

Microtubules with Bt-tubulin

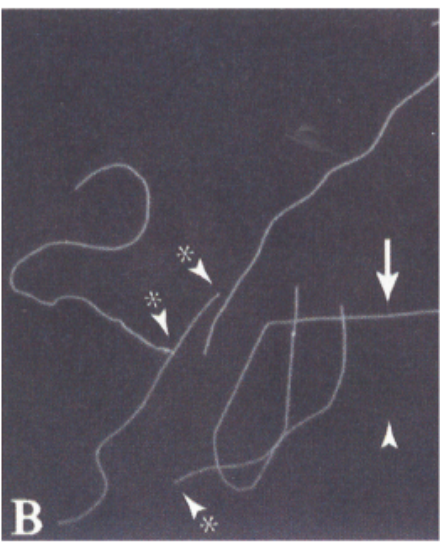

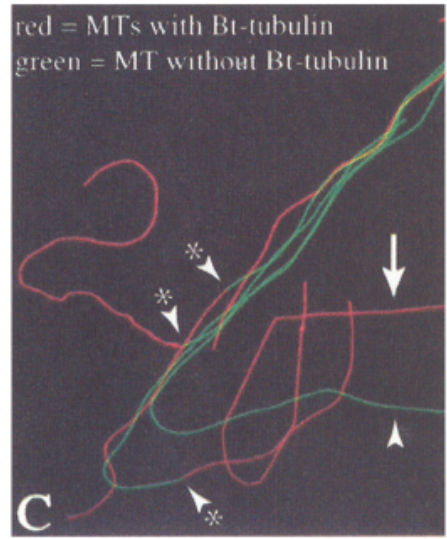


and Hirokawa, 1990, 1992). Thus, in addition to its overall stabil ity, the MT array in growing axons exhibits a dynamic quality as well. Specifically, the mechanisms that generate the MT array during axon growth can restructure the entire MT array of the axon during a period of only a few hours. This in turn provides the growing axon with the flexibility to adjust its internal architecture, and thereby its shape, according to morphogenetic cues encountered as it elongates toward its target.

Thus far, we have considered how MT assembly and turnover in neurons are specialized for axon growth. However, other processes also contribute to the generation of the MT array required for axon growth. Most notably in this respect is the transport of tubulin from its sites of synthesis in the cell body into the axon. At the very least, this process provides the axon with the tubulin subunits required to generate the MT array of the axon. It also has been hypothesized that tubulin is transported in the form of MTs and that the MT transport mechanisms directly generate several features of the axonal MT array. Considerable controversy surrounds this hypothesis because of the mixed results obtained by investigators attempting to demonstrate MT movement in axons (Lim et al., 1990; Okabe and Hirokawa, 1990, 1992; Reinsh et al., 1991; Baas and Ahmad, 1993; Ahmad and Baas, 1995; Sabry et al., 1995; Takeda et al., 1995). At present it is not possible to resolve this controversy satisfactorily. If we assumc that MTs are actively transported in axons, however, then the following considerations provide a sense of the magnitude by which new MTs are delivered to the axon by the polymer transport mechanisms.

As discussed above, the MT array in growing axons undergoes extensive turnover, such that during a period of several hours most MTs depolymerize entirely. Because the axon continues to elongate despite this turnover, and because elongation is accompanied by an increase in both the number and the length of MTs in the axon (Stevens et al., 1988), the mechanisms that generate the MT array must add sufficient new polymer to the axon to more than replace what is lost by turnover. Several observations suggest that within the axon MT assembly occurs exclusively by elongation from the ends of MTs, and that self-assembly of tubulin into new MTs or assembly of MTs from structures other than MTs does not occur (for review, see Black, 1994). Thus, local assembly mechanisms, in and of themselves, are not sufficient to account for the replacement of MTs lost by turnover because they cannot generate new MTs within the axon. Rather, we suggest that these new MTs are delivered principally by transport from the cell body, with local assembly mechanisms modulating their length. If this is correct, then the delivery of new MTs by the polymer transport mechanisms is sufficiently robust to more than offset the loss of MTs attributable to local turnover and, thereby, increase the number of MTs in the axon as it elongates. The massive increase in the number of MTs in the axon that occurs during the early phases of axon outgrowth (Stevens et al., 1988; Yu and Baas, 1994) also indicates the vigor with which new MTs are delivered to the axon by the MT transport mechanisms. Although indirect, these considerations suggest that polymer transport mechanisms have a substantial role in both maintaining and expanding the MT array during axon growth.
Finally, it is important to note that the data presented here came from immature neurons maintained in culture for $\sim 1 \mathrm{~d}$. How these findings generalize to neurons at different stages in their growth and maturation is unknown. Intuitively, it is reasonable that the dynamic properties of MTs in growing axons will differ from those in more mature neurons that have established synaptic contacts and have stopped growing. In this respect, several developmentally related changes in axonal MTs have been documented. For example, the sensitivity of axonal MTs to MTdestabilizing conditions declines with age (Black and Greene, 1982; Stevens et al., 1988; Watson et al., 1990). Also, the composition and relative abundance of various MT-associated proteins (MAPs) change during development (for review, see Matus, 1988; Tucker, 1990). Because MAPs can influence MT stability under in vitro and in vivo conditions (for review, see Hirokawa, 1994), developmentally related changes in their composition may result in corresponding changes in MT stability. These considerations suggest that the dynamic properties of axonal MTs change during neuronal growth and maturation. We assume that the properties of axonal MTs revealed in the present studies reflect specializations concerned with axonal morphogenesis. Future work will reveal how the dynamic properties change as the neuron matures and the axon establishes synaptic contacts and stops growing.

\section{REFERENCES}

Ahmad FJ, Baas PW (1995) Microtubules released from the neuronal. centrosome are transported into the axon. J Cell Sci 108:2761-2769.

Arregui C, Busciglio J, Caceres $\Lambda$, Barra HS (1991) Tyrosinated and detyrosinated microtubules in axonal processes of cerebellar macroneurons grown in culture. J Neurosci Res 28:171-181.

Baas PW, Ahmad FJ (1993) The transport properties of axonal microtubules establish their polarity orientation. J Cell Biol 120:1427-1437.

Baas PW, Black MM (1990) Individual microtubules in the axon consist of domains that differ in both composition and stability. $J$ Cell Biol 111:495-509.

Baas PW, Slaughter T, Brown A, Black MM (1991) Microtubule dynamics in axons and dendrites. J Neurosci Res 30:134-153.

Black MM (1994) Microtubule assembly and transport cooperate to generate the microtubule array of the axon. Prog Brain Res 102:61-77.

Black MM, Cochran JM, Kurdyla JT (1984) Solubility properties of neuronal tubulin: evidence for labile and stable microtubules. Brain Res 295:255-263.

Black MM, Greene LA (1982) Changes in the colchicine susceptibility of microtubules associated with neurite outgrowth: studies with nerve growth factor responsive $\mathrm{PC} 12$ pheochromocytoma cells. J Cell Biol 95:379-386.

Black MM, Slaughter T, Fischer I (1994) Microtubule-associated protein $1 b$ (MAP1b) is concentrated in the distal region of growing axons. J Neurosci 14:857-870.

Blose SH, Meltzer DI, Feramisco JR (1984) Ten nm filaments are induced to collapse in living cells microinjected with monoclonal and polyclonal antibodies against tubulin. J Cell Biol 98:847-858.

Bray D, Bunge MB (1981) Serial analysis of microtubules of cultured rat sensory neurons. J Neurocytol 10:589-605.

Bré M-H, Kreis T, Karsenti E (1987) Control of microtubule nucleation and stability in Madin-Darby canine kidney cells: the occurrence of non-centrosomal, stable detyrosinated microtubules. J Cell Biol $105: 1283-1296$.

Brinkley BR (1985) Microtubule organizing centers. Annu Rev Cell Biol $1: 145-172$.

Figure 10. High-magnification view of axonal MTs processed according to the Ab-blocking procedure at 8 hr after injection. The region depicted in this figure corresponds to a portion of the hatched area in Figure 8. $A$, MT polymer without Bt-tub; $B$, polymer with Bt-tub; $C$, multicolor overlay in which polymer without Bt-tub is depicted in green and polymer with Bt-tub is depicted in red. The arrow and arrowhead identify MT profiles with or without $\mathrm{Bt}$-tub, respectively; these are the same profiles identified in Figure 8. The arrowheads with asterisks point to individual MTs that contain Bt-tub only over part of their length; the tip of each arrowhead points to the transition between the portion of the polymer with Bt-tub and the portion without Bt-tub. 
Brown A, I i Y, Slaughter T, Black MM (1993) Composite microtubules of the axon: quantitative analysis of tyrosinated and acetylated $\alpha$-tubulin along axonal microtubules. J Cell Sci 104:339-352.

Brown $\Lambda$, Slaughter T, Black MM (1992) Newly assembled microtubules are concentrated in the proximal and distal regions of growing axons. J Cell Biol 119:867-882.

Burton PR, Paige JL (1981) Polarity of axoplasmic microtubules in the olfactory nerve of the frog. Proc Natl Acad Sci USA 78:3269-3273.

Cassimeris L, Pryer NK, Salmon ED (1988) Real-time observations of microtubule dynamic instability in living cells. $J$ Cell Biol 107:2223-2231.

Cassimeris LU, Wadsworth P, Salmon ED (1986) Dynamics of microtubule depolymerization in monocytes. J Cell Biol 102:2023-2032.

Edson KJ, Lim S-S, Borisy GG, Letourneau PC (1993) FRAP analysis of the stability of the microtubule population along the neurites of chick sensory neurons. Cell Motil Cytoskel 25:59-72.

Geuens G, Hill AM, Levilliers N, Adoutte A, DeBrabander M (1989) Microtubule dynamics investigated by microinjection of Paramecium axonemal tubulin: lack of nucleation put proximal assembly of microtubules at the kinetochore during prometaphase. J Cell Biol 108:939-953.

Gundersen GG, Khawaja S, Bulinski JC (1987) Post-polymerization detyrosination of $\alpha$-tubulin: a mechanism for subcellular differentiation of microtubules. J Cell Biol 105:251-264.

Heidemann SR, Hamborg MA, Thomas SJ, Song B, Lindley S, Chu D (1984) Spatial organization of axonal microtubules. J Cell Biol 99:1289-1295.

Hirokawa N (1994) Microtubule organization and dynamics dependent on microtubule associated proteins. Curr Opin Cell Biol 6:74-81.

Hyman A, Drechsel D, Kellogg D, Salser S, Sawin K, Steffen P, Wordeman L, Mitchison T (1991) Preparations of modified tubulins. Methods Enzymol 196:478-485.

Joshi HC, Baas PW (1993) $\Lambda$ new perspective on microtubules and axon growth. J Cell Biol 121:1191-1196.

Kirschner M, Mitchison T (1986) Beyond self assembly: from microtubules to morphogenesis. Cell 45:329-342.

Kreis T (1987) Microtubules containing detyrosinated tubulin are less dynamic. EMBO J 6:2597-2606.

Lim S-S, Edson KJ, Letourneau PC, Borisy GG (1990) A test of microtubule translocation during neurite elongation. J Cell Biol 111:123-130.

Lim S-S, Sammak PJ, Borisy GG (1989) Progressive and spatially differentiated stability of microtubules in developing neuronal cells. $\mathbf{J}$ Cell Biol 109:253-263.

Mains RF., Patterson PH (1973) Primary cultures of dissociated sympathetic neurons. I. Establishment of long-term growth in culture and studies of differentiated properties. J Cell Biol 59:329-345.

Matus $\Lambda$ (1988) Microtubule-associated proteins: their potential role in determining neuronal morphology. Annu Rev Neurosci 11:29-44.

Mitchison T, Kirschner MW (1984) Microtubule assembly nucleated by isolated centrosomes. Nature 312:232-237.

Mobley WC, Shenker A, Shooter EM (1976) Characterization and isolation of proteolytically modified" nerve growth factor. Biochemistry 15:5543-5551.

Morris JR, Lasek RJ (1984) Monomer-polymer equilibria in the axon: direct measurement of tubulin and actin as polymer and monomer in axoplasm. J Cell Biol 98:2064-2076.

Okabe S, Hirokawa N (1988) Microtubule dynamics in nerve cells: analysis using microinjection of hiotinylated tubulin into PC12 cells. I Cell Biol 107:651-664.

Okabe S, Hirokawa N (1990) Turnover of fluorescently labelled tubulin and actin in the axon. Nature 343:479 482 .
Okabe S, Hirokawa N (1997) Differential behavior of photoactivated microtubules in growing axons of mouse and frog neurons. $\mathrm{J}$ Cell Biol $117: 105-120$.

Pepperkok R, Bré MH, Davouse J, Kreis TE (1990) Microlubules are stabilized in confluent epithelial cells but not in fibroblasts. J Cell Bio 111:3003-3012.

Prescott AR, Dowrick PG, Warn RM (1992) Stable and slow-turning over microtubules characterize the processes of motile epithelial cells treated with scatter factor. J Cell Sci 102:103-112.

Reinsch SS, Mitchison TJ, Kirschner MW (1991) Microtubule polymer assembly and transport during axonal elongation. Cell Biol 115:365-379.

Sabry J, O'Connor TP, Kirschner MW (1995) Axonal transport of tubulin in Til pioneer neurons in situ. Neuron 14:1247-1256.

Sahenk Z, Brady ST (1987) Axonal tubulin and microtubules: morphological evidence for stable regions on axonal microtubules. Cell Motil Cytoskeleton 8:155-164.

Salmon ED, Leslie RJ, Saxton WM, Karow ML, McIntosh JR (1984) Spindle microtubule dynamics in sea urchin embryos: analysis using a fluorescein-labeled tubulin and measurements of fluorescence redistribution after laser photobleaching. J Cell Biol 99:2165-2174.

Schliwa M, van Blerkom JJ (1981) Structural interactions of cytoskeletal components. J Cell Biol 90:222-235.

Schulze E, Asai DJ, Bulinski JC, Kirschner M (1987) Post-translational modification and microtubule stability. J Cell Biol 105:2167-2177.

Schulze E, Kirschner MW (1987) Dynamic and stable populations of microtubules in cells. J Cell Biol 104:277-288.

Sheldon E, Wadsworth P (1993) Observation and quantification of individual microtubule behavior in vivo: microtubule dynamics are cell type-specific. J Cell Biol 120:935-945.

Sherwin T, Gull K (1989) Visualization of detyrosination along single microtubules reveals novel mechanisms of assembly during cytoskeletal duplication in trypanosomes. Cell 57:211-221.

Sherwin T, Schneider A, Sasse R, Seebeck T, Gull K (1987) Distinct localization and cell cycle dependence of C-terminally tyrosylated $\alpha$-tubulin in microtubules of Trypanosoma brucei. J Cell Biol 104:439-446.

Stevens JK, Trogadis J, Jacobs JR (1988) Development and control of axial neurite form: a serial electron microscopic analysis. In: Intrinsic determinants of neuronal form and function (Lasek RJ, Black MM, eds), pp 115-146. New York: Liss.

Takeda S, Funakoshi T, Hirokawa N (1995) Tubulin dynamics in neuronal axons of living zebrafish embryos. Neuron 11:1257-1264.

Tsukita S, Ishikawa H (1981) The cytoskeleton in myelinated axons: serial section study. Biomed Res 2:424-437.

Tucker RP (1990) The role of microtubule-associated proteins in brain morphogenesis: a review. Brain Res Rev 15:109-120.

Wadsworth P, McGrai] M (1990) Interphase microtubule dynamics are cell type-specific. J Cell Sci 95:23-32.

Watson DF, Hoffman PN, Griffin JW (1990) The cold stability of microtubules increases during axonal growth. J Neurosci 10:3344 3352.

Webster DR, Gundersen GG, Bulinski JC, Borisy GG (1987) Differential turnover of tyrosinated and detyrosinated microtubules. Proc Natl Acad Sci USA 84:9040-9044.

Wehland J, Weber K (1987) Turnover of the carboxy-terminal tyrosine of $\alpha$-tubulin and means of reaching elevated levels of detyrosination in living cells. J Cell Sci 88:185-203.

Yu W, Baas PW (1994) Changes in microtubule number and length during axon differentiation. J Neurosci 14:2818 2829. 